\title{
A poultry litter marker gene correlates with pathogen and indicator bacteria deposition on, growth in and transport from poultry bedding
}

\author{
Kameswari Sirisha Mantha \\ West Virginia University
}

Follow this and additional works at: https://researchrepository.wvu.edu/etd

\section{Recommended Citation}

Mantha, Kameswari Sirisha, "A poultry litter marker gene correlates with pathogen and indicator bacteria deposition on, growth in and transport from poultry bedding" (2014). Graduate Theses, Dissertations, and Problem Reports. 113.

https://researchrepository.wvu.edu/etd/113

This Thesis is protected by copyright and/or related rights. It has been brought to you by the The Research Repository @ WVU with permission from the rights-holder(s). You are free to use this Thesis in any way that is permitted by the copyright and related rights legislation that applies to your use. For other uses you must obtain permission from the rights-holder(s) directly, unless additional rights are indicated by a Creative Commons license in the record and/ or on the work itself. This Thesis has been accepted for inclusion in WVU Graduate Theses, Dissertations, and Problem Reports collection by an authorized administrator of The Research Repository @ WVU. For more information, please contact researchrepository@mail.wvu.edu. 


\title{
A poultry litter marker gene correlates with pathogen and indicator bacteria deposition on, growth in and transport from poultry bedding
}

\author{
Kameswari Sirisha Mantha \\ Thesis submitted \\ to the Benjamin M. Statler College of Engineering and Mineral Resources \\ at West Virginia University \\ in partial fulfillment of the requirements for the degree of \\ Masters of Science in \\ Civil and Environmental Engineering
}

Jennifer Weidhaas, Ph.D., P.E., Chair

Antarpreet Jutla, Ph.D.

Alan Sexstone, Ph.D.

Department of Civil and Environmental Engineering

Morgantown, West Virginia

2014

Keywords: Feces deposition, Microbial source tracking, Poultry litter marker genes, Soil column, Pathogens, FIB

Copyright 2014 Sirisha Mantha 


\begin{abstract}
A poultry litter marker gene correlates with pathogen and indicator bacteria deposition on, growth in and transport from poultry bedding.
\end{abstract}

\title{
Kameswari Sirisha Mantha
}

Poultry is one of the major contributors of inputs to U.S. environmental waters due to the large number of poultry grown per year in the U.S. and litter disposal practices. Two studies were conducted during this research: (1) to determine the temporal rate of deposition and growth or decay of microorganisms in poultry litter originating from poultry feces and (2) the release and transport of poultry litter associated microorganisms from soiled poultry litter applied as fertilizer through soil columns under simulated rainfall. First, deposition studies were conducted to evaluate the deposition rate of microorganisms on poultry bedding during the growth of poultry. The studies were designed to simultaneously evaluate the growth or decay of microorganisms after deposition on the poultry bedding (i.e., wood shavings). A secondary objective of this study was to determine if there is a correlation between the poultry litter marker gene and indicator bacteria (FIB) and pathogens during deposition. Culture and qPCR analysis revealed growth of Enterococcus, Staphylococcus and Bacteroidales in the litter for up to four weeks after deposition in feces. In contrast after deposition of $E$. coli on the litter, the concentrations of $E$. coli declined after the soiled litter was separated from the poultry. The poultry litter marker Brevibacterium sp. LA35 was found to increase in the litter over time as the birds aged, but was not observed to grow in the soiled litter after deposition with feces. The deposition study aids in our understanding of the deposition, survival and growth of microorganisms from poultry feces in and on poultry litter. The next study conducted evaluated the release and transport of pathogens (Salmonella sp.), FIB (Enterococcus, and E. coli) and MST 
markers (LA35 and Bacteroidales) from poultry litter under simulated rainfall events through soil columns. The transport and attenuation of microorganisms was observed through an acid washed sand column and loamy sand soil columns over 10 to 30 pore volumes of deionized water. The qPCR analysis revealed that the breakthrough of pathogens and MST markers were correlated. These soil column studies aid in our understanding of the release, transport and attenuation of pathogens from poultry litter applied as an agricultural fertilizer. 


\section{ACKNOWLEDGEMENTS}

I would like to express my utmost appreciation to my advisor, Dr. Jennifer Weidhaas, for her patience, knowledge, motivation, and cheerful attitude that directed the completion this research. I thank her for the systematic guidance, enthusiasm, great effort and immense knowledge she put into training me in the scientific field. I could not have imagined having a better advisor and mentor for my study. I also would like to thank Dr. Alan Sexstone and Dr. Antarpreet Jutla for their valuable time and serving on my committee.

I would like to thank Dr. Jianbo Yao, Division of Animal \& Nutritional Sciences and his students for allowing me to use nanodrop quantification spectrophotometer to complete analysis at his laboratory. My thanks go to Dr. Lian-Shin Lin and his students for allowing me to use their lab to setup my soil column experiment.

Finally, I take this opportunity to express the profound gratitude to my dear husband Ashwin Kumar, for his tremendous support anytime needed, my daughter Anjali, my beloved parents, Sreenivas and Kamakshi and siblings for their love, encouragement, understanding and continuous support during all this years. I really appreciate the help of my friends and fellow students: Thomas, Autumn, Emily, Elliott, and Pujya. Last but not least, my thanks go to all the other faculty and staff in Civil and Environmental Engineering at WVU, graduate students, each and every one of them has had an impact on me. 


\section{Contents}

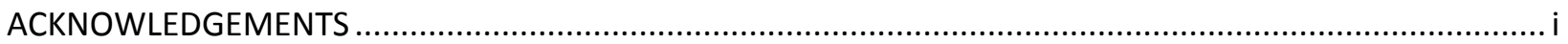

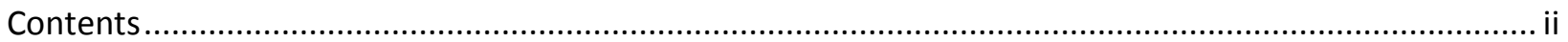

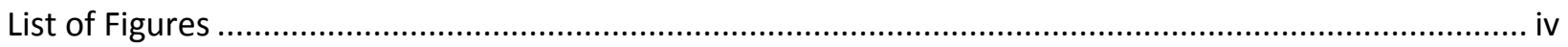

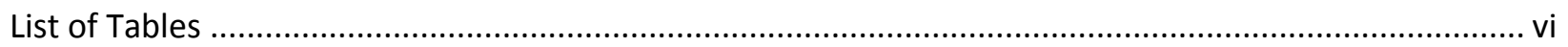

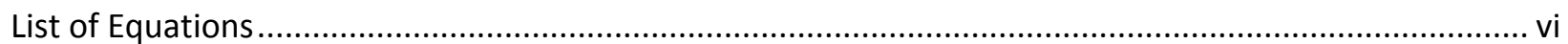

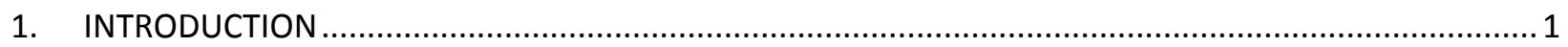

1.1 Movement and persistence of bacteria in groundwater and soils .............................................. 2

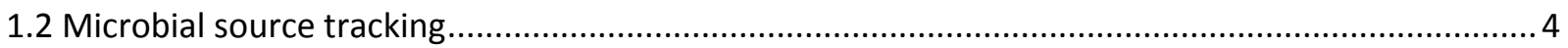

1.3 Identification of the poultry litter marker gene and development of qPCR assay .......................... 6

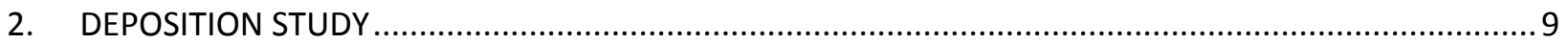

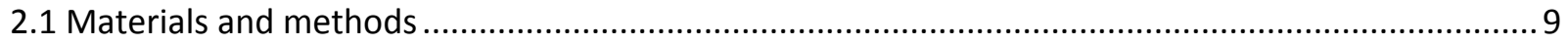

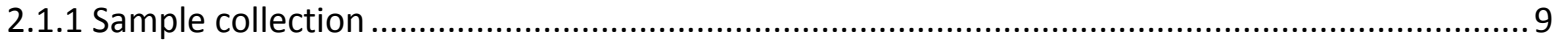

2.1.2 Poultry feces deposition and incubation study ....................................................................

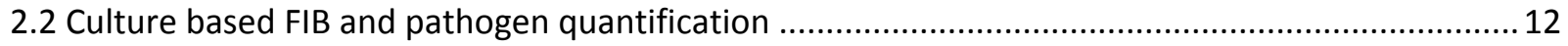

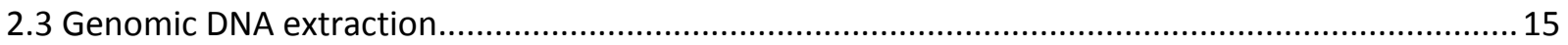

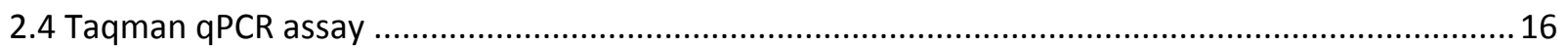

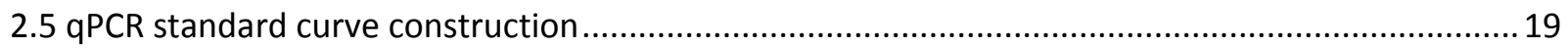

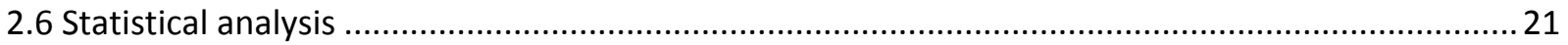




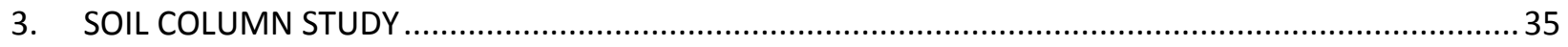

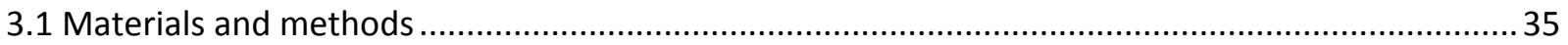

3.1.1 Determining the properties of sand and loamy-sand........................................................ 36

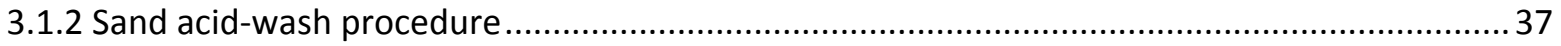

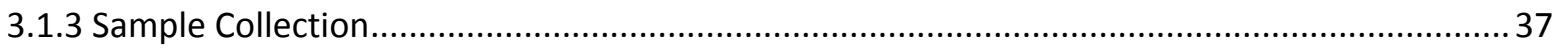

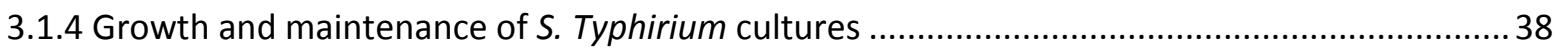

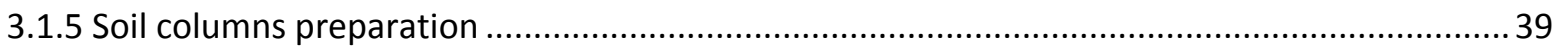

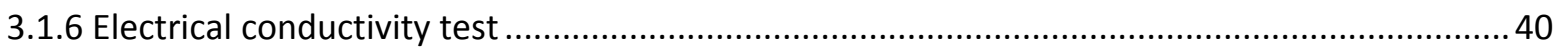

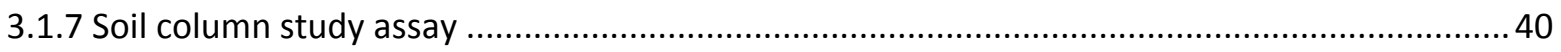

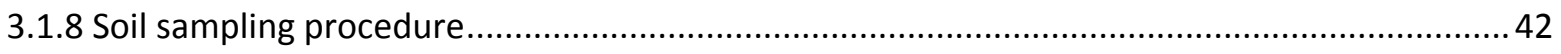

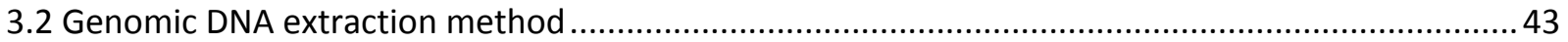

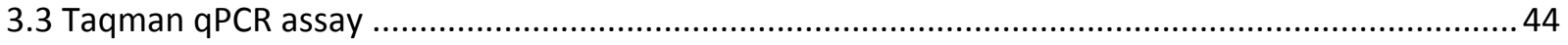

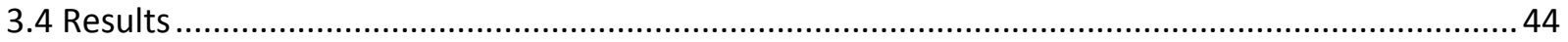

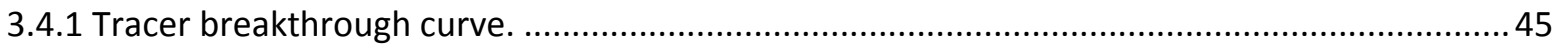

3.4.2 Microbial concentrations in poultry litter. ........................................................................... 46

3.4.3 Microbial concentrations in the leachate from the soil columns. ......................................... 47

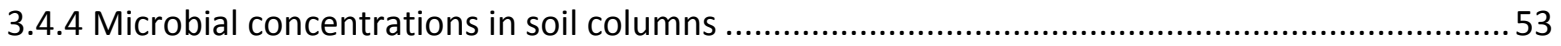

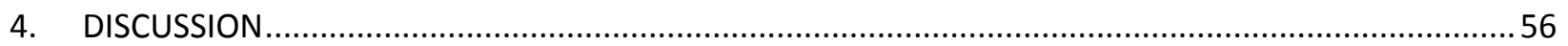

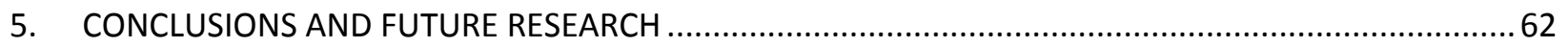




\section{List of Figures}

Figure 1.1 Pathogen transfer controls from agricultural settings (modified from Oliver et al., 2005)......... 3

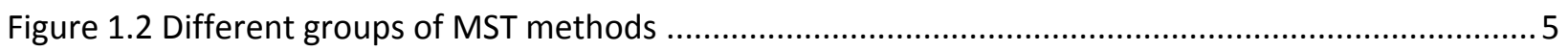

Figure 2.1 Poultry litter sample composited and placed in a sterile centrifuge tube sealed with sterile

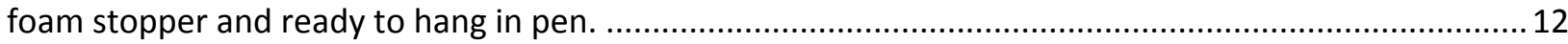

Figure 2.2 Poultry litter sample tubes hung in pen $0.3 \mathrm{~m}$ above the ground level................................. 12

Figure 2.3 Standard curve for Brevibacterium sp. LA35(A), E. coli(B), Enterococcus sp.(C), Bacteroidales(D)

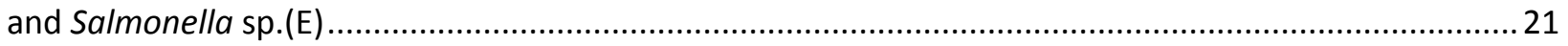

Figure 2.4 Variations in temperatures $\left({ }^{\circ} \mathrm{F}\right)$ in the chicken house during 25 days ..................................2 23

Figure 2.5 Concentration of $E$. coli observed by culture and qPCR methods in the poultry litter below the birds (FW) and in litter incubated in tubes in the pens (W1, W2, W3, W4). The horizontal dash-dot line indicates the minimum detection limit for the culture based methods and dashed line is for qPCR

method.

Figure 2.6 Correlation between E. coli and Enterococcus sp. present in the FW samples and the incubated samples tested by culture based methods.

Figure 2.7 Concentrations of Enterococcus sp. by culture and qPCR methods. Poultry litter below the birds (FW) and in litter incubated in tubes in the pens (W1, W2, W3, W4). The dashed-dot lines at the bottom in the graphs were minimum detection limits of enterococci by Culture-based method and dashed line was by qPCR methods. 
Figure 2.8 Correlation of Staphylococcus sp. with E. coli and Enterococcus sp. in FW samples and correlation of Staphylococcus sp. with E. coli samples that were incubated in hung tubes by culture based methods

Figure 2.9 Concentrations of Staphylococcus by culture methods. Poultry litter below the birds (FW) and in litter incubated in tubes in the pens (W1, W2, W3, W4). The straight dashed-dot line at the bottom represents minimum detection limits for culture based methods.

Figure 2.10 Concentrations of Bacteroidales by qPCR methods. Poultry litter below the birds (FW) and in litter incubated in tubes in the pens (W1, W2, W3, W4). The dashed straight lines at the bottom represent the minimum detection limits of the samples for Bacteriodales qPCR method. 32

Figure 2.11 Correlation of LA35 with E. coli and Enterococcus sp in all the samples that were tested in deposition study. Error! Bookmark not defined. Figure 2.12 Concentrations of Brevibacterium sp. in poultry litter by qPCR methods. Poultry litter below the birds (FW) and in litter incubated in tubes in the pens (W1, W2, W3, W4)...... .34

Figure 3.1 Schematic diagram of soil column study .35

Figure 3.2 Soil column experiment setup in laboratory. 36

Figure 3.3 Example soil sections after removal from the PVC column with 1 representing the top of the column and containing litter and 5 representing the bottom of the column. 43

Figure 3.4 Electrical Conductivity of $1 \mathrm{M} \mathrm{NaCl}$ solution in Sand column 46

Figure 3.5 Initial microbial concentrations in poultry litter used in the soil column studies 47 Figure 3.6 Leachate samples collected from replicate loamy-sand column study. The samples proceed in order from first collected on the left to last collected on the right in the figure. 48 Figure 3.7 Represents relative changes in log gene copies $\mathrm{L}^{-1}$ of microbial concentrations in leachate samples from sand column (A), loamy-sand column (B), replicate loamy-sand column (C)....................50 Figure 3.8 Correlation of LA35 with E. coli, Enterococcus sp., Bacteroidales and S. Typhirium. .51 
Figure 3.9 Correlation of LA35 with E. coli and Bacteroidales sp. in the leachate samples collected in the loamy-sand column study. .52

Figure 3.10 Correlation of $L A 35$ with E. coli and Bacteroidales sp. in the leachate samples that were collected during replicate loamy-sand column study.

Figure 3.11 Represents relative changes in log gene copies $\mathrm{L}^{-1}$ of microbial concentrations in leachate samples from sand column (A), loamy-sand column (B), replicate loamy-sand column (C). $C_{0}$ is the microbial concentrations present in the first leachate samples collected.

Figure 3.12 Concentrations of LA35 (A), Bacteroidales (B), E. coli (C), Enterococcus sp. (D), and Salmonella sp. (E) in sand column (squares) and loamy-sand column (diamonds) with depth. The dashed trendline is added for sand column and solid trendline is added for loamy-sand column. .55

\section{List of Tables}

Table 2.1 Deposition sampling scheme 101

Table 2.2 Culture-based methods for bacterial targets 13

Table 2.3 Targeted organisms, genes targeted, and primers and probe sequences used in the qPCR assay

Table 2.4 List of ingredients present in chicken feed during the growth of birds. 24

Table 3.1 Different sieves used for sieving and the size of particles retained on them ...... 45

\section{List of Equations}

Equation 1 Thomas Equation for calculating MPN concentrations.

Equation 2 Slope equation .2

Equation 3 Equation to calculate average DNA in gene copies per L or g of litter...... .19

Equation 4 Calculate LOI \% from soil samples. .37 


\section{INTRODUCTION}

Poultry plays a vital role in the United States agricultural economy. In 2014, broiler meat production was forecast at 38.9 billion pounds in the United States (USDA 2014). Land application of -contaminated poultry bedding (litter) can contribute to pollution of surface waters and groundwater's during rain events (Weidhaas et al., 2011). Environmental degradation may result when the limits for poultry litter land application are exceeded (Wood et al., 1992). Typical poultry litter often includes wood shavings, peanut hulls, rice hulls, or various other locally available manure absorbents introduced into the poultry production houses to facilitate manure removal at the end of a growing period. Previous research has shown that the poultry litter contains various bacteria, viruses, and fungi such as Brevibacterium sp. LA35 (Weidhaas et al., 2009), Bacteroidales (Kelty et al., 2012), E. coli (Kelty et al., 2012), Enterococcus sp. (Kelty

et al., 2012), Salmonella (Kelley et al., 1995), Staphylococcus sp. and Campylobacter sp. (Kelley et al., 1995) some of which are potentially pathogenic to human and poultry. Re-utilization of poultry litter as poultry bedding, feed additive, and fertilizers may cause transport of pathogens to poultry, crops, soils, surface water and groundwater and finally to human consumers (Kelley et al., 1995).

Since the passage of Clean Water Act in 1972, water quality has become a top priority in United States. However, the CWA water quality criteria based on pollutant levels is not met in many lakes, rivers and streams (USEPA 2000B). Contamination of water is of great concern in waters used for human recreation, drinking, and aquaculture (Simpson et al., 2002). contamination can add human pathogens (bacterial, viral and eukaryotic) to water, posing a threat to public health (Brown et al., 2004). Current regulatory strategies for pathogens depend 
on culture based methods for detection of total and coliforms and indicator bacteria (FIB) such as enterococci and E. coli. These indicator organisms are surrogates for pathogens in current regulatory strategies for recreational and source water quality assessment (USEPA 2002). These are the drawbacks to the use of FIB for water quality assessment. For example, long analytical turnaround times ( $>24 \mathrm{hr}$ ) are associated with culture dependent FIB methods (Weidhaas et al., 2011). For remediation of polluted waters and for accurate human health risk assessments, knowledge of the contamination source is necessary (USEPA 2005). To overcome drawbacks associated with culture dependent regulatory standards, alternative methods such as quantitative polymerase chain reaction (qPCR) of general and host-specific DNA markers are used, which allowed more rapid and more accurate assessments of water microbiological quality (Weidhaas et al., 2011).

\subsection{Movement and persistence of bacteria in groundwater and soils}

Microorganisms and pathogens originating from material are transported to surface water and groundwater via many routes (Hornberger et al., 1992). The transfer of microorganisms from agriculture wastes to surface and groundwater is thought to be due to manure loading of grasslands by poultry and livestock manure (Oliver et al., 2005).

The transport mechanisms of microorganisms within soil can be divided into physical, geochemical and biological processes (Tim et al., 1998). Physical processes include advection, whereby the bulk water carries potential pathogens. Under advective transport microorganism movement is a function of the water velocity, and the microorganisms are dispersed as they move along the water path. Filtration and sedimentation mechanisms as geophysical processes and sorption as a geochemical process may slow microbial transport through the soil matrix. In 
biological processes the growth and chemotactic responses of one bacterium may influence the transfer of other microorganisms through the soil habitat (Reynolds et al., 1989). Therefore, the potential movement of pathogens in soils and groundwater is subject to a series of spatial and temporal controls (Figure 1.1).

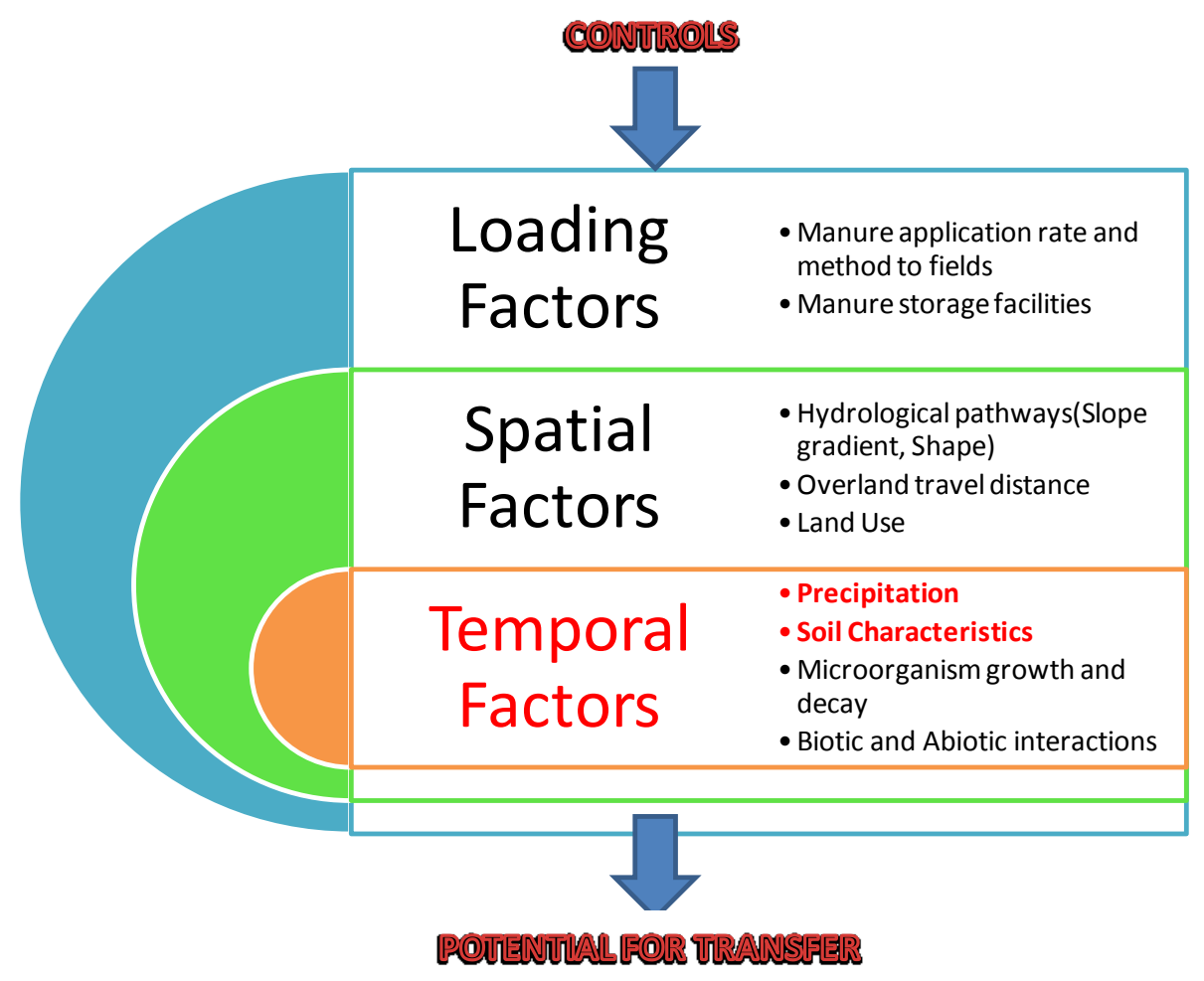

Figure 1.1 Pathogen transfer controls from agricultural settings (modified from Oliver et al., 2005).

Large scale bacterial movement in soil (i.e., over distances larger than a few microns) is controlled by the soil moisture content. The overall soil moisture content is important because the microbial population is limited to the aqueous phase and the solid-liquid interface. For appreciable bacterial movement in soil to occur there needs to be enough water-filled pores of sufficient diameter to enable a contiguous flow pathway (Bowen and Rovira 1999). It has been reported that more cells are transferred in leachate from later or subsequent rain events compared 
to cell numbers recorded in the first rainfall event (Saini et al., 2003). Additionally it was found that the microorganisms move farther in saturated soils compared to drier soils, likely due to the increase in occurrence of percolating water (Culley and Philips 1982).

In highly permeable soils, pathogenic microorganisms and similarly non-pathogens move to surface water via overland flow pathways and via subsurface transport. The pollution of surface waters from manure on grassland soils is largely facilitated by rainfall. It was reported that slow flow microbial transfers operating between storm events are thought to be associated with the steady percolation of water through the soil profile. In contrast the physical movement of soils, manures, and potential pathogens into streams, creating a more rapid and direct transfer route occurs after high energy precipitation events. For example, FIB concentrations in stream water passing through a catchment area with significant livestock grazing activity and manure spreading as fertilizer were monitored in a research by Rodgers et al., 2003. It was reported that heavy rainfall events are capable of increasing bacteria levels by 100 -fold in this study area.

\subsection{Microbial source tracking}

The group of methods that targets the genes of microorganisms specific to the feces and gastrointestinal tract of a particular host animal are called microbial source tracking (MST) methods. The concept that pollution can be traced using "microbiological, genotypic, phenotypic, and chemical methods" (Scott et al., 2002) describes the term MST. Microbial source tracking is also sometimes referred to as bacterial source tracking. MST methods have been most commonly used to supplement traditional FIB methods. These methodologies are designed to identify and quantify the dominant sources of contamination in groundwater, recreational water, wild life habitat waters and drinking water. 
There are two major groups of MST methods: library-dependent and library-independent (Figure 1.2). Culturing methods are library-dependent. Methods based on detection of a specific host-associated genetic marker or DNA (Stoeckel et al., 2007) are library-independent methods. MST methods that are used for discriminating among different groups of bacteria are called phenotypic and genotypic methods. Multiple antibiotic resistance analysis (MAR) and immunological procedures are two phenotypic methods. Pulsed-field gel electrophoresis (PFGE), host specific molecular markers and repetitive element PCR and qPCR are some of many genotypic methods that can be used in MST.

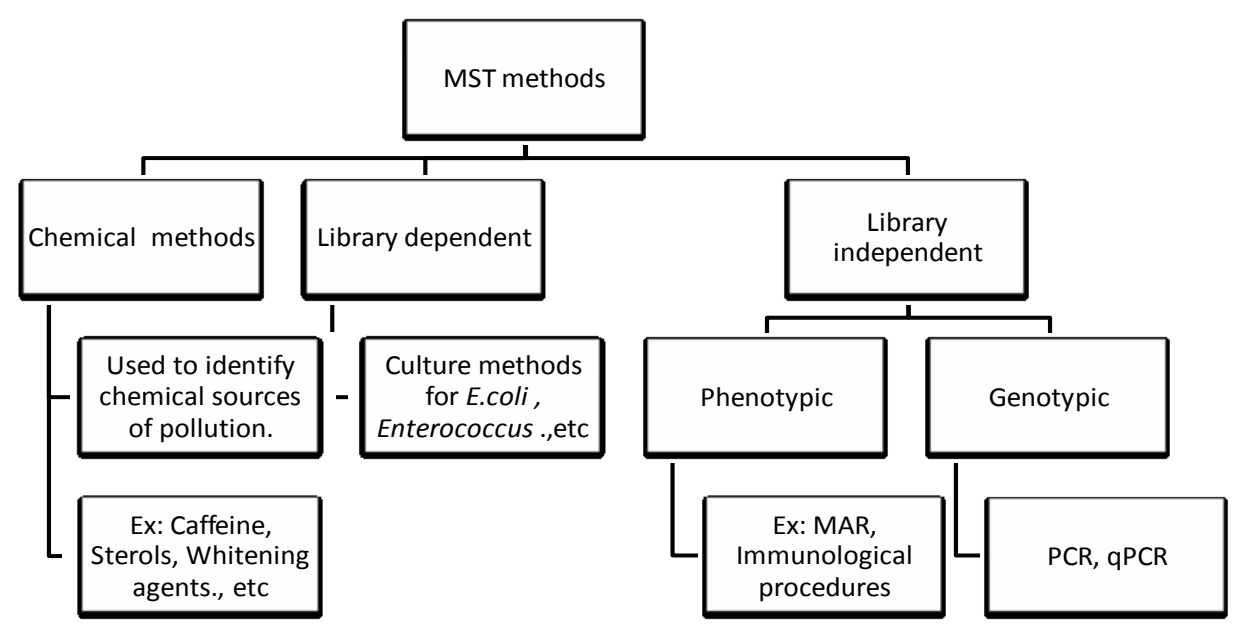

Figure 1.2 Different groups of MST methods

To help identify non-point sources responsible for pollution of water the EPA has written guidance on the use of MST (USEPA 2005). According to 2005 EPA MST guidance document the key characteristics that are specified for ideal source trackers are:

\section{Host specificity}

2. Distribution in all host species members or waste 
3. Marker is rarely subject to mutation or methodological variability

4. Temporal marker stability in the host

5. No geographic variability in marker/host association

6. Diversity of the marker in the host and in water is represented by a small sample size

7. Limited or a predictable rate of decay in environment

8. Abundance in primary and secondary habitat is related

9. Marker can be used to regulate water quality

10. The maker itself constitutes a health risk

The EPA MST criteria 1, 2, 5, and 9 have been evaluated in previous studies and the results of those studies are discussed in the next section. The research presented herein was designed to address criteria 4,8 , and 9 .

\subsection{Identification of the poultry litter marker gene and development of qPCR assay}

A SYBR green qPCR-based assay for the 16SrRNA gene of the poultry litter associated Brevibacterium sp. LA35 was developed by Weidhaas, et al. (2010). LA35 was found to be prevalent in chicken and turkey litter (100\%) and chicken samples (60\%), and was found to be host specific (i.e., $6.9 \%$ are false positive results from non-target sample testing). Additionally, the marker was found in 10 edge-of-field runoff samples from areas that had received poultry litter as a fertilizer. A more recent study reported detections of the LA35 marker gene in $40 \%$ of stream samples tested in an intensive poultry rearing region (Weidhaas et al., 2011). In this study the LA35 assay's specificity to poultry litter was further evaluated against samples from a wide range of non-target animal samples. Using the 16S rRNA gene sequences of Brevibacterium sp. LA35 obtained from chicken litter samples a more specific $\operatorname{TaqMan}^{\circledR}$ based qPCR assay was developed and validated against non-target samples. In a more recent study conducted by 
Weidhaas and Lipscomb (2013) the TaqMan $^{\circledR}$ based qPCR assay was tested on fecally contaminated environmental waters of an intensive poultry rearing region of West Virginia which drains to the Chesapeake Bay. A total of 28 poultry litter samples and 126 non target fecal samples were investigated. It was observed that LA35 was sensitive (76\%) and specific $(100 \%)$ to poultry litter. A sufficiently low $\left(2.5 \times 10^{-2} \mathrm{mg}\right.$ litter $\left.\mathrm{l}^{-1}\right)$ detection limit for poultry litter in water samples was observed indicating the method is useful for water monitoring. The LA35 gene was found in $43 \%$ of water samples $(n=30)$ from the Potomac River headwaters in West Virginia. In a recent study two poultry litter assays qPCR targeting the 16S rRNA gene of Brevibacterium sp. LA35 was compared. A total of 226 chicken litter $(n=40)$ and chicken samples $(n=186)$ were investigated. It was observed that most chicken litter samples (i.e., $98 \%)$ were positive for both assays with relatively high signal intensities, whereas only $23 \%$ and $12 \%$ of poultry samples $(n=186)$ were positive with the LA35 and CL assays. It was also observed that these assays are highly host associated $(>95 \%)$ from the $(n=484)$ samples tested from nontarget sources (Ryu et al., 2013).

While the previous studies indicate that the LA35 marker gene assay is both specific to poultry litter and sensitive enough for environmental water quality monitoring in poultry impacted watersheds, several key criteria need to be evaluated. First, does the LA35 marker gene concentration change after deposition in feces by poultry (i.e., temporal stability, primary and secondary habitat)? Second, is the LA35 marker gene correlated with pathogens and FIB and therefore could it be used to regulate or investigate water quality? 
Two studies were conducted to evaluate these questions. The microorganisms evaluated in this study included pathogens (Salmonella sp.), FIB (Escherichia coli, Enterococcus sp.) and the MST markers (Brevibacterium sp. LA35 and Bacteroidales)

The goals of the deposition study were to:

- Evaluate the deposition rate of microorganisms on unused litter from feces during the growth of poultry.

- Evaluate growth and/or decay of microorganisms after deposition on the litter.

- Evaluate the correlation of the poultry litter marker gene with FIB and pathogens.

The goals of the soil column study were to:

- Evaluate the release and transport of microorganisms from poultry litter under simulated rainfall events through soil columns.

- Compare the release and transport of LA35 with respect to other microorganisms.

The remaining chapters in this thesis detail the materials and methods, results and discussion for each of these two studies separately. Specifically, the materials and methods and results of the deposition study is presented first in Chapter 2, while the soil column study is presented in Chapter 3. The interpretation of the results of both of these studies is presented in the discussion section in Chapter 4. While conclusions and recommendations for future research are presented in Chapter 5. 


\section{DEPOSITION STUDY}

\subsection{Materials and methods}

\subsubsection{Sample collection}

Composite poultry litter samples were collected from the WVU Animal Sciences Farm (Morgantown, WV). Eight different pens were randomly chosen, among them four pens consisted of male roosters and the other 4 consisted of female chickens. Composite samples were obtained by collecting eight (ea. $4 \mathrm{~g}$ ) scoops of poultry litter from different pens in a sterile, stainless steel bowl (Figure 2.1), removing the loose feathers and large wood chips and then mixing the feces thoroughly to homogenize the sample. A subsample $(6 \mathrm{~g})$ was then taken from the bowl and placed in sterile, nonpyrogenic $15 \mathrm{~mL}$ centrifuge tubes (Corning Incorporated, Corning, NY). All samples were held on ice for no longer than 3 hours prior to DNA extraction on the day of collection. Extra samples that were not extracted for DNA the day of collection were stored in a $-80^{\circ} \mathrm{C}$ freezer, without further preparation.

\subsubsection{Poultry feces deposition and incubation study}

Poultry litter samples were collected once per week for a period of 7 weeks starting immediately after 2 day old chicks were placed on unsoiled wood shavings. These samples are referred to as fresh litter samples (i.e., FW) hereafter. Prior to placement of the birds on the unsoiled wood shavings the barn was sanitized by disinfectant (Virocid, CID Lines N.V., Belgium). Along with the fresh litter samples, subsamples were hung in $15 \mathrm{ml}$ centrifuge tubes (Corning Incorporated, Corning, NY) in the pens approximately $0.3 \mathrm{~m}$ from the ground (Figure 2.1). The tubes contained sub-sampled FW litter that was collected every week to compare the 
amounts of decomposition and decay in poultry litter over a period of time without inputs of additional material from the poultry. These subsamples are referred to as "WX-Y" hereafter, where $\mathrm{X}$ indicates the week in which the litter was hung in the pen and $\mathrm{Y}$ indicates the week in which the sample was collected for analysis. During week 1 , seven replicates of the composite sample was made (W1-Y) and one sample was taken to the lab on week 1 for further analysis (FW1), whereas 6 other samples were placed in $15 \mathrm{ml}$ tubes and hung in tubes in different pens (W1 to 7). Each tube was collected during each subsequent weekly visit for rest of the six weeks of the study. Similarly during week 2 , a total of two samples were taken to lab, one fresh sample (FW2) and the other is from one of the tubes that were hung in pens during the week 1 sampling (W1-2). Additionally during week 2, five replicates of week 2 fresh samples were hung in pens for further analysis. This process of sample collection continued for a period of seven weeks. Birds were present on the litter for a period of six weeks only. The week 2 through 5 tubes were sealed with sterile foam stoppers (Figure 2.2) to allow for air exchange. The week 1 tubes were sealed with a plastic screws cap which would have limited air exchange. 
Table 2.1 Deposition sampling scheme

\begin{tabular}{|c|c|c|c|c|c|c|c|}
\hline \multirow[t]{2}{*}{$\begin{array}{c}\text { Tasks in } \\
\text { Field/Lab }\end{array}$} & \multicolumn{7}{|c|}{ Age of birds in weeks } \\
\hline & Week 1 & Week 2 & Week 3 & Week 4 & Week 5 & Week 6 & Week 7 \\
\hline $\begin{array}{c}\text { Date of } \\
\text { sampling/ } \\
\text { DNA } \\
\text { extraction }\end{array}$ & $2 / 26 / 13$ & $3 / 05 / 13$ & $3 / 14 / 13$ & $3 / 21 / 13$ & $3 / 28 / 13$ & $4 / 04 / 13$ & $4 / 11 / 13$ \\
\hline $\begin{array}{c}\text { Fresh } \\
\text { samples } \\
\text { labeled as }\end{array}$ & FW1 & FW2 & FW3 & FW4 & FW5 & FW6 & FW7 \\
\hline $\begin{array}{l}\text { Samples } \\
\text { that were } \\
\text { hung in } \\
\text { pens in } \\
\text { sterile } \\
\text { stoppered } \\
\text { tubes }\end{array}$ & $\begin{array}{l}\text { W1-CW2 } \\
\text { W1-CW3 } \\
\text { W1-CW4 } \\
\text { W1-CW5 } \\
\text { W1-CW6 } \\
\text { W1-CW7 }\end{array}$ & $\begin{array}{l}\text { W2-CW3 } \\
\text { W2-CW4 } \\
\text { W2-CW5 } \\
\text { W2-CW6 } \\
\text { W2-CW7 }\end{array}$ & $\begin{array}{l}\text { W3-CW4 } \\
\text { W3-CW5 } \\
\text { W3-CW6 } \\
\text { W3-CW7 }\end{array}$ & $\begin{array}{l}\text { W4-CW5 } \\
\text { W4-CW6 } \\
\text { W4-CW7 }\end{array}$ & $\begin{array}{l}\text { W5-CW6 } \\
\text { W5-CW7 }\end{array}$ & W6-CW7 & $\begin{array}{c}\text { No } \\
\text { samples } \\
\text { were hung } \\
\text { in pens. }\end{array}$ \\
\hline $\begin{array}{c}\text { Samples } \\
\text { taken to } \\
\text { lab for } \\
\text { DNA } \\
\text { extraction }\end{array}$ & FW1 & $\begin{array}{c}\text { FW2 } \\
\text { W1-CW2 }\end{array}$ & $\begin{array}{c}\text { FW3 } \\
\text { W1-CW3 } \\
\text { W2-CW3 }\end{array}$ & $\begin{array}{c}\text { FW4 } \\
\text { W1-CW4 } \\
\text { W2-CW4 } \\
\text { W3-CW4 }\end{array}$ & $\begin{array}{c}\text { FW5 } \\
\text { W1-CW5 } \\
\text { W2-CW5 } \\
\text { W3-CW5 } \\
\text { W4-CW5 }\end{array}$ & $\begin{array}{c}\text { FW6 } \\
\text { W1-CW6 } \\
\text { W2-CW6 } \\
\text { W3-CW6 } \\
\text { W4-CW6 } \\
\text { W5-CW6 }\end{array}$ & $\begin{array}{c}\text { FW7 } \\
\text { W1-CW7 } \\
\text { W2-CW7 } \\
\text { W3-CW7 } \\
\text { W4-CW7 } \\
\text { W5-CW7 } \\
\text { W6-CW7 }\end{array}$ \\
\hline
\end{tabular}

A sample of wood shavings used as bedding for the chicks, prior to exposure to poultry was collected aseptically. The poultry litter feed was also collected at the end of the study from one random pen. Both the samples were investigated for the presence of microorganisms by the same qPCR methods used on the soil litter samples. 


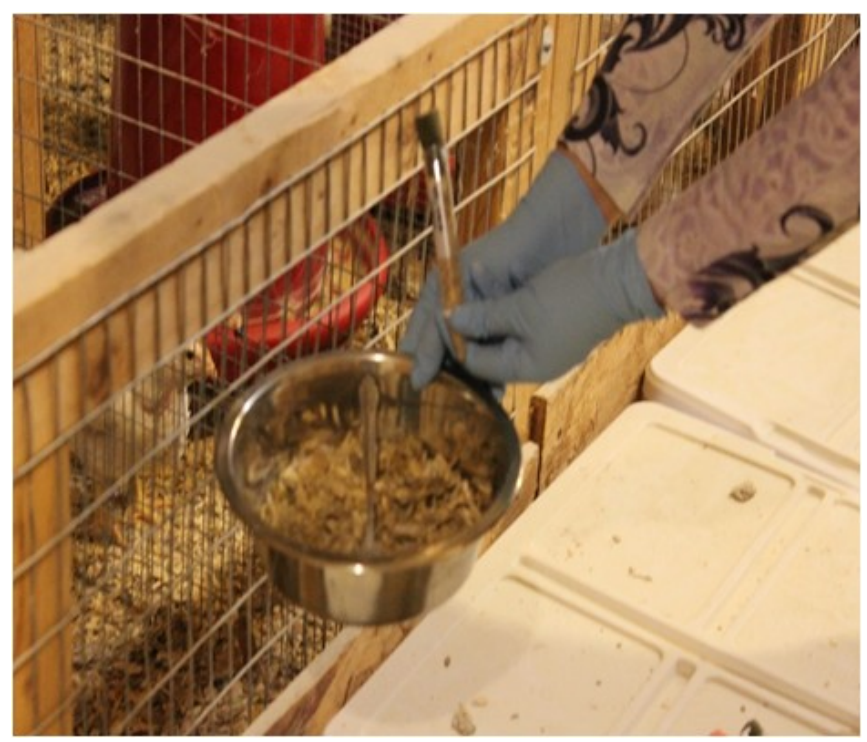

Figure 2.1 Poultry litter sample composited and placed in a sterile centrifuge tube sealed with sterile foam stopper and ready to hang in pen.

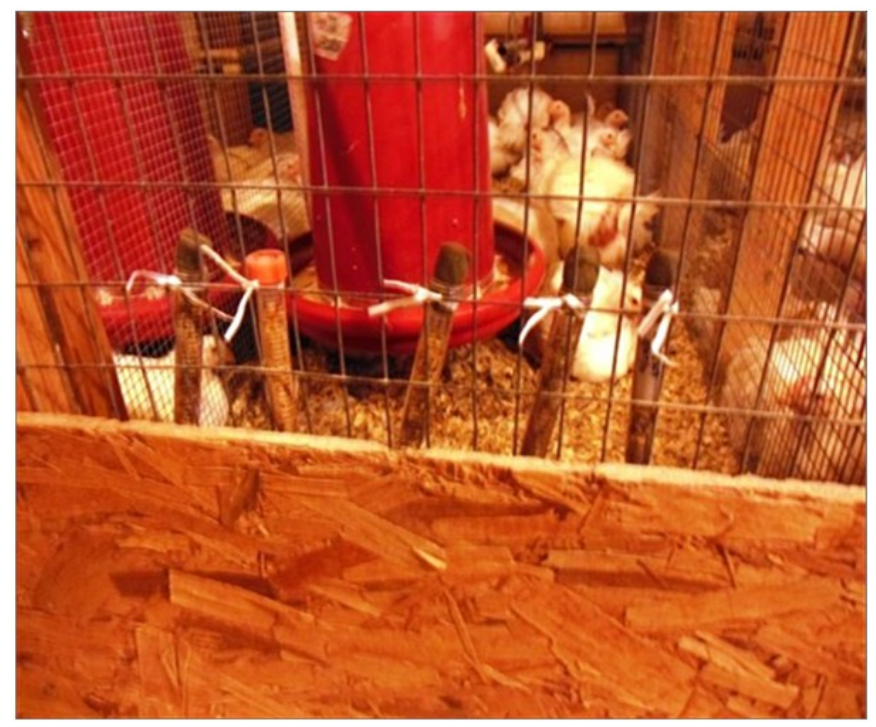

Figure 2.2 Poultry litter sample tubes hung in pen $0.3 \mathrm{~m}$ above the ground level.

\subsection{Culture based FIB and pathogen quantification}

The methods used to culture FIB and pathogens in this study are listed in Table 2.2, and described briefly below. 
Table 2.2 Culture-based methods for bacterial targets

\begin{tabular}{|c|c|c|}
\hline Target bacteria & Culture-based method & References \\
\hline E. coli & EPA Method 1103.1 & USEPA. 2002. \\
\hline Enterococcus $\mathrm{sp}$. & EPA Method 1600 & USEPA. 2006. \\
\hline Salmonella sp. & $\begin{array}{c}\text { Enrichment in RV-broth, isolation on } \\
\text { XLT4 agar. }\end{array}$ & APHA. 2005. \\
\hline Staphylococcus sp. & $\begin{array}{c}\text { Enrichment on m-staphylococcus } \\
\text { broth, isolation on mannitol salt agar. }\end{array}$ & APHA. 2005. \\
\hline
\end{tabular}

E. coli culturing. Difco ${ }^{\mathrm{TM}}$ mTEC Agar (Becton, Dickson and Company, Sparks, MD) was prepared according to the instructions on the manufacturers' bottle. Each petri dish (Fisher Brand, Fairlawn, NJ) consisted of 4-6 mL of solidified agar. The urea substrate solution was stored at $6-8{ }^{\circ} \mathrm{C}$ for no more than one week. E. coli was cultured in the laboratory exactly according to the method proposed by (USEPA. 2006. Method 1600). The sample bottle is shaken vigorously at least 25 times to distribute the bacteria uniformly and $20 \mathrm{~mL}$ of sample was placed into the funnel. To obtain a more accurate count of bacteria, a 5 fold MPN dilution method was used in which 5 replicates of sample were obtained for each dilution. E. coli produces yellow, yellow-green, or yellow-brown colonies on urea substrate medium. The number of colonies were counted and recorded on those membrane filters containing 20 to 80 yellow, yellow-green, or yellow-brown colonies.

Enterococcus sp. culturing. Difco ${ }^{\mathrm{TM}} \mathrm{mEI}$ Agar (Becton, Dickson and Company, Sparks, MD) was prepared according to the manufacturer's instructions. After sterilization of mEI agar, $0.24 \mathrm{~g} \mathrm{~L}^{-1}$ of nalidixic acid (Acros organics, NJ, USA) and $0.02 \mathrm{~g} \mathrm{~L}^{-1}$ triphenyltetrazoliumchloride (Tokyo chemical industry Ltd, Kita-Ku, Tokyo, Japan.) is added to the mEI medium and mixed thoroughly. The mEI agar is dispensed into $15 \times 60 \mathrm{~mm}$ petri dishes 
to a 4-5 mm depth (approximately 4-6 mL), and allowed it to solidify. After incubation, the number of colonies are counted and recorded for those membrane filters containing, 20-60 colonies each. Only colonies of approximately $0.5 \mathrm{~mm}$ in diameter with a blue halo regardless of colony color was counted. When measuring colony size, the halo was not included in the estimate.

Salmonella culturing. Difco ${ }^{\mathrm{TM}}$ XLT4 agar (Becton, Dickson and Company, Sparks, MD) and RV broth (Oxoid Ltd, Basingstoke, Hants, England) were prepared according to the manufacturer's instructions. Approximately, $10 \mathrm{~mL}$ of sterile RV broth is poured into sterile glass screw cap bottles and $1 \mathrm{~mL}$ of diluted sample is added to $\mathrm{RV}$ broth and incubated at $37^{\circ} \mathrm{C}$ for 24 hours. A loopful of grown culture is streaked onto the XLT4 agar plate and incubated at $37^{\circ} \mathrm{C}$ for 24 hours. Salmonella produces foul smelling black round colonies on XLT4 agar plates.

Staphylococcus culturing. M-Staphylococcus broth (Remel, Richmond, VA) and mannitol salt agar (Remel, Richmond, VA.) were prepared according to the manufacturer's instructions. Approximately, $10 \mathrm{~mL}$ of sterile m- Staphylococcus broth is poured into sterile glass screw cap bottles and $1 \mathrm{~mL}$ of diluted sample is added to it. The broth is incubated at $35 \pm$ $1{ }^{\circ} \mathrm{C}$ for 24 hours. A loopful of grown culture is streaked onto mannitol salt agar plates and incubated at $35 \pm 1$ for 48 hours. Staphylococcus produces opaque zones in 24 hours and yellow zones after 48 hours of incubation around Staphylococcus colonies.

MPN Method. The most probably number (MPN) method was used to quantify the concentration of E. coli, Enterococcus sp., Salmonella sp., and Staphylococcus sp. Samples were prepared by adding $1 \mathrm{~g}$ of poultry litter to $50 \mathrm{~mL}$ of sterile $1 \mathrm{X}$ phosphorus buffered saline (PBS) 
solution. Initially 3 dilutions $\left(10^{-1}, 10^{-2}\right.$, and $\left.10^{-3}\right)$ were made, and then dilutions were increased to $10^{-9}$ depending on the expected concentrations of bacteria (Equation 2.1) in the litter. The three greatest dilutions in which growth was observed were taken into MPN analysis. A replicate of 5 plates of each diluted samples were analyzed for E. coli and Enterococcus sp. whereas for Salmonella and Staphylococcus replicate of 5 tubes of broth was incubated for each diluted sample. The numbers of positive and negative plates are counted after incubation. The MPN g ${ }^{-1}$ value of concentration of bacteria present in poultry litter is calculated using Thomas equation (Thomas et al., 1942) divided by the grams of poultry litter used in making the initial sample solution as shown (Equation 1).

$$
\begin{gathered}
\frac{M P N}{g}=\frac{\text { Number Of positive tubes }}{\sqrt{\text { mL.of sample in negative tubes } \times \text { mL.of samples in all tubes }}} \\
\quad \times \frac{50 \mathrm{ml} \text { of } 1 X \text { PBS }}{\text { gof litter used for diluting litter }}
\end{gathered}
$$

Equation 1

\subsection{Genomic DNA extraction}

Genomic DNA from poultry litter samples was extracted using the Qiagen DNeasy Blood and Tissue kit following the manufacturer's instructions. DNA was extracted from approximately $0.25 \mathrm{~g}$ of material (poultry feces and wood shavings). Purification of the DNA was carried out using ethanol precipitation (Liu et al., 1997). Purified DNA was quantified at $260 \mathrm{~nm}$ using a Nanodrop ND-1000 UV Spectrometer (Nanodrop Technologies, Wilmington, $\mathrm{DE})$. 


\subsection{Taqman qPCR assay}

The qPCR primers and probes use in this study are presented in Table 2.3. All the primers and probes used in this study were commercially synthesized from IDT (Integrated DNA Technologies, USA). qPCR amplification reaction mixtures ( $25 \mathrm{uL})$ contained template DNA (1 uL), $1 \times$ TaqMan universal master mix (Applied Biosystems, Foster City, CA), primers at final concentrations of $0.5 \mathrm{uM}$ for LA35 and $1 \mathrm{uM}$ otherwise, and various concentrations of Taqman probes (i.e., $250 \mathrm{nM}$ for E. coli, Salmonella sp., and LA35, and $80 \mathrm{nM}$ for Enterococcus sp. and Bacteroidales sp.). All reactions were carried on a 7300 Real Time PCR System (Life Technologies, Grand Island, NY). A plasmid (LA35, Enterococci, Bacteroidales) or culture (E. coli and Salmonella sp.) containing target gene sequences was used as the positive control in all reactions. PCR grade water was used as negative control. Thermocycler conditions for different target bacteria matched those presented in the references in Table 2.3. All the samples are tested along with duplicate matrix-spiked samples (i.e., LA35 containing plasmid added to template DNA) to determine if the DNA extracted samples were inhibited in the qPCR reaction.

Positive controls for $E$. coli and S. Typhirium qPCR. LB broth (Fisher Scientific, Pittsburgh, PA) is inoculated with an E. coli colony taken from a urea substrate medium plate and grown for a maximum of 12 hours at $44.4^{\circ} \mathrm{C}$. RV- broth was inoculated with a loopful of $S$. Typhirium culture (ATCC number 14028) and allowed it to grow for 24 hours at $37^{\circ} \mathrm{C}$. These cultures after 12 or 24 hours were considered to be the initial samples and a 5 fold MPN serial dilutions were conducted to determine the initial concentrations of microbes present in the culture. Additionally, $2 \mathrm{~mL}$ of sample of the growth culture was taken into DNA extraction by 
the freeze-thaw and boil-cool method as mentioned in Polijak et al., 1995 and Gautam PW 2013. This DNA sample was used in generating the standard curves. 
Table 2.1 Targeted organisms, genes targeted, and primers and probe sequences used in the qPCR assay

\begin{tabular}{|c|c|c|c|c|}
\hline Assay name & Target name & Primer and probe sequences(5'-3') & $\begin{array}{l}\text { qPCR-based } \\
\text { method, } \\
\text { target-gene }\end{array}$ & References \\
\hline $\begin{array}{l}\text { GenBacF3 } \\
\text { GenBacR4 } \\
\text { GenBacP2 }\end{array}$ & $\begin{array}{l}\text { Bacteroidales } \\
\text { sp. }\end{array}$ & $\begin{array}{c}\text { GGGGTTCTGAGAGGAAGGT } \\
\text { CCGTCATCCTTCACGCTACT } \\
\text { FAM-CAATATTCCTCACTGCTGCCTCCCGTA-BHQ-1 }\end{array}$ & $\begin{array}{c}\text { Taqman qPCR } \\
16 \mathrm{~S} \text { rRNA }\end{array}$ & $\begin{array}{l}\text { Siefring et al., } \\
2008\end{array}$ \\
\hline $\begin{array}{c}\text { Eco-F } \\
\text { Eco-R } \\
\text { Eco-PR }\end{array}$ & E. coli & $\begin{array}{c}\text { GTCCAAAGCGGCGATTTG } \\
\text { CAGGCCAGAAGTTCTTTTTCCA } \\
\text { FAM-ACGGCAGAGAAGGTA- BHQ-1 }\end{array}$ & $\begin{array}{c}\text { Taqman qPCR } \\
\text { uidA }\end{array}$ & Lee et al., 2006 \\
\hline $\begin{array}{l}\text { Entero 1A } \\
\text { Entero R1 } \\
\text { GPL813TQ }\end{array}$ & $\begin{array}{l}\text { Enterococcus } \\
\text { sp. }\end{array}$ & $\begin{array}{c}\text { GAGAAATTCCAAACGAACTTG } \\
\text { CAGTGCTCTACCTCCATCATT } \\
\text { FAM-TGGTTCTCTCOGAAATAGCTTTAGGGCTA-BHQ- } \\
1 \\
\end{array}$ & $\begin{array}{c}\text { Taqman qPCR } \\
\text { 23S rRNA }\end{array}$ & $\begin{array}{c}\text { Ludwig and } \\
\text { Schleifer } 2000\end{array}$ \\
\hline $\begin{array}{l}\text { LA35F } \\
\text { LA35R } \\
\text { LA35P }\end{array}$ & $\begin{array}{c}\text { Brevibacterium } \\
\text { sp. LA35 }\end{array}$ & $\begin{array}{c}\text { ACCGGATACGACCATCGC } \\
\text { TCCCCAGTGTCAGTCACAGC } \\
\text { FAM-CAGCAGGGAAGAAGCCTTCGGGTGACGGTA- } \\
\text { BHQ-1 }\end{array}$ & $\begin{array}{l}\text { Taqman } \\
\text { qPCR } \\
\text { 16S rRNA }\end{array}$ & Ryu et al., 2014 \\
\hline $\begin{array}{c}\text { Sal-F } \\
\text { Sal-R } \\
\text { Sal-Probe } \\
\end{array}$ & Salmonella sp. & $\begin{array}{c}\text { CGTTTCCTGCGGTACTGTTAATT } \\
\text { AGACGGCTGGTACTGATCGTAA } \\
\text { FAM-CCACGCTCTTTCGTCT-BHQ-1 } \\
\end{array}$ & $\begin{array}{c}\text { Taqman qPCR } \\
\text { inv } A\end{array}$ & $\begin{array}{l}\text { Lee et al., } 2005 \\
\text { Shannon et al., } \\
2007\end{array}$ \\
\hline
\end{tabular}




\section{5 qPCR standard curve construction}

Plasmids containing the target genes (i.e., 16S rRNA genes of LA35 and Bacteroidales, and the 23S rRNA gene of Enterococcus sp.) or cultures with known concentrations of microorganisms were used for qPCR. For E. coli and Salmonella sp. the DNA was extracted from the cultured colonies using the freeze-thaw and boil-cool method as described above. The plasmids and cultures were used to gene rate standard curves for qPCR by serially diluting the plasmids or cells from $10^{11}$ to $10^{12}$ gene copies $\mathrm{ul}^{-1} \mathrm{qPCR}$ reaction. It was assumed that each cell of E. coli or Salmonella sp. contained one copy of the $16 \mathrm{~S}$ rRNA or invA gene, respectively.

Duplicate qPCR reactions were performed for the serially diluted plasmid standard (Figure 2.3). The efficiency of the assays and the coefficient of determination $\left(\mathrm{R}^{2}\right)$ of the standard curves were calculated based on linear regressions. Perfect amplification must double the starting DNA in every cycle. Consequently, amplification curves for all standards samples should be evenly separated by 3.32 cycles in order to obtain an efficiency of $100 \%$. The amplification efficiency $(E)$ was calculated from the slope of the standard curve using the formula in Equation 2. To calculate the gene copies per gram of litter Equation 3 was used. Log gene copies $(5 \mathrm{ul})^{-1}$ are the values are calculated from the appropriate standard curves. In reporting the results for which microbial concentrations were not detected by qPCR methods, the concentrations were set to one half the detection limits for each assay. The detection limits for each method were represented by dashed lines in the results graphs.

Efficiency $(E)=-1+10^{-1 / \text { slope }}$

Equation 2 


$$
D N A \frac{\text { copy }}{\text { L or } g}=\frac{[(\log \text { copies }) / 5 u l] \times D F \times(\text { vol of DNA after cleanup }(u l))}{\text { Amount filtered or extracted in } L \text { or } g}
$$

Equation 3
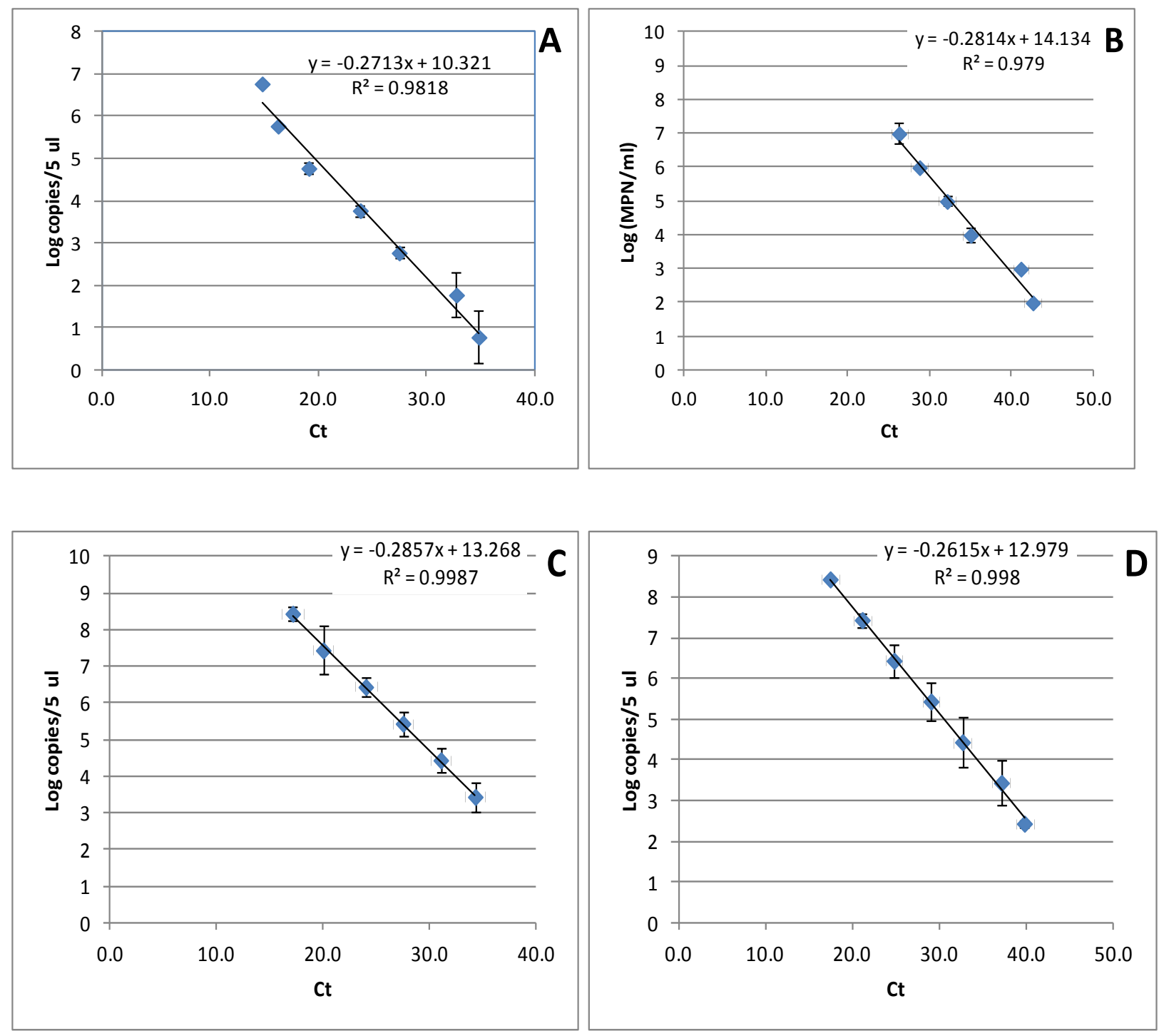


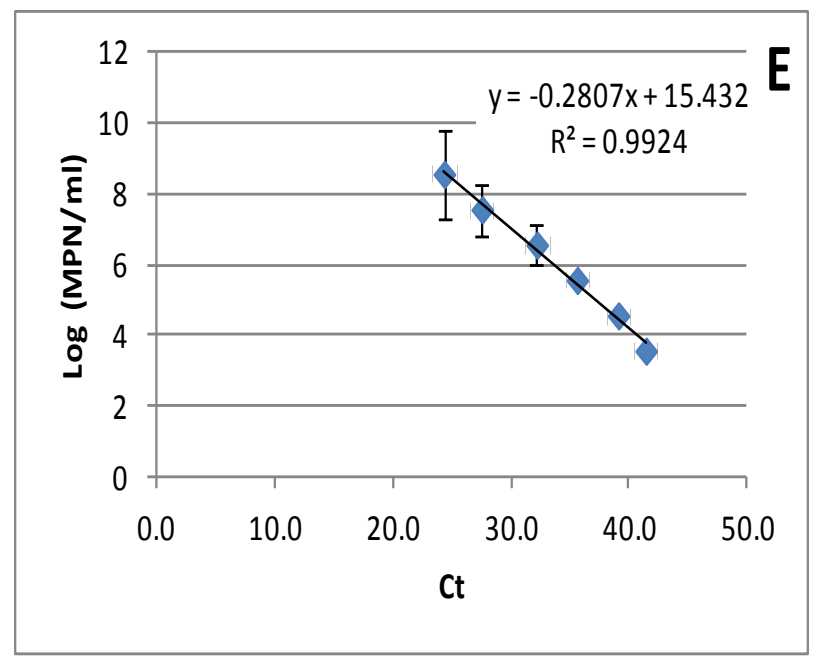

Figure 2.3 Standard curve for Brevibacterium sp. LA35 (A), E. coli (B), Enterococcus sp. (C), Bacteroidales (D) and Salmonella sp. (E)

The estimated efficiency for the qPCR reactions were $88.95 \%$ for Brevibacterium sp. LA35, $93.86 \%$ for E. coli, $93.20 \%$ for Enterococcus sp., $82.80 \%$ for Bacteroidales and $91.78 \%$ for Salmonella sp.

\subsection{Statistical analysis}

Statistical correlations were estimated by the Pearson product moment correlation coefficient which is a measure of the linear correlation (dependence) between two variables $X$ and $Y$, giving a value between +1 and -1 inclusive, where 1 is total positive correlation, 0 is no correlation, and -1 is total negative correlation (Karl Pearson 1985). Pearson's $r$ and $\mathrm{P}$ values have been calculated for different sets in both deposition and soil column studies. It was observed that the pair(s) of variables with positive correlation coefficients and $\mathrm{P}$ values below 0.050 tends to increase together. For the pairs with negative correlation coefficients and $\mathrm{P}$ values below 0.050 , one variable tends to decrease while the other increases. For pairs with $\mathrm{P}$ values greater than 0.050 , there is no significant relationship between the two 
variables. Statistics were calculated using Sigma Plot version 11 (SYSTAT Software, Inc., Chicago, IL, USA).

\subsection{Results}

A total of 27 fresh and in-house incubated poultry litter samples were collected from WVU animal science's farm and were evaluated for the deposition of pathogens (Salmonella and Staphylococcus), FIB (Enterococcus sp., and E. coli) and MST markers (LA35 and Bacteroidales) by juvenile checks on unsoiled wood shavings over 7 weeks. All the samples were tested by qPCR for the presence of pathogens, FIB and MST markers, while E. coli, Enterococcus sp., and Salmonella sp. were enumerated using culture based methods. Salmonella sp. were not detected in any of the poultry litter samples. Each subsection below presents the concentrations of these organisms observed in the deposition study.

Prior to starting this study poultry bedding that was exposed to one day old chicks was collected from disinfected pens. DNA was extracted from this litter sample and qPCR was conducted to quantify target microorganisms. Concentrations of E. coli, Enterococcus sp., and Bacteroidales were observed to be 7.01, 8.34, 6.56 log gene copies (g wood shavings) ${ }^{-1}$, respectively. A feed sample was sample was collected from one pen at the end of the study and was investigated by qPCR for the presence of the target microorganisms. None of microorganisms targeted in this study were detected by qPCR in the feed sample.

Temperatures. The temperatures in the house was recorded during the first 24 days or till the birds reach their maturation stage. The temperatures in the hen house were very high varying from $95^{\circ} \mathrm{F}$ to $88^{\circ} \mathrm{F}$ during first week of birds. The temperatures were decreased to $70^{\circ} \mathrm{F}$ 
during the next two weeks and were maintained at $70^{\circ} \mathrm{F}$ to $74^{\circ} \mathrm{F}$ until the birds were slaughtered.

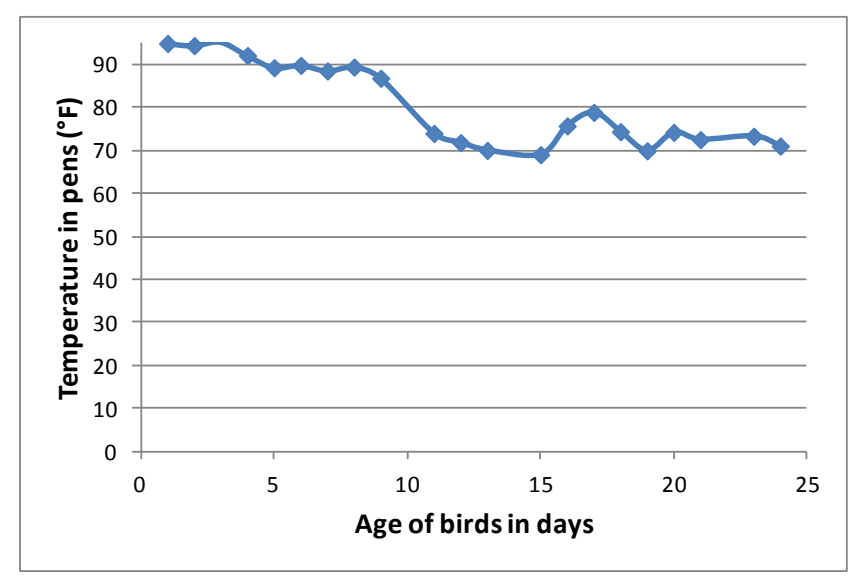

Figure 2.4 Variations in temperatures $\left({ }^{\circ} \mathrm{F}\right)$ in the chicken house during 25 days

Chicken feed. All the chickens were given the same feed. However their feed varied depending on the age of birds. The diet was kept as an unprocessed mash or pelleted /ground in the WVU pilot feed mill. The lists of various ingredients present in the chicken feed are listed in Table 2.4. The digestible proteins or amino acids are mentioned with prefix "dig" in the Table 2.4. In "DL" in the term "methionine DL" means it is a racemic mixture of D and $\mathrm{L}$ configuration of methionine, The "L" in "L Lysine" and "L Threonine" L means the L configuration of that amino acid. 
Table 2.2 List of ingredients present in chicken feed during the growth of birds.

\begin{tabular}{|c|c|c|c|}
\hline & From $2 / 22$ to $3 / 3$ & From $3 / 4$ to $3 / 14$ & From $3 / 15$ to $4 / 5$ \\
\hline \multicolumn{4}{|c|}{ Ingredients (\%) } \\
\hline Corn & 56.34 & 61.04 & 67.44 \\
\hline Soybean Meal & 32.81 & 262 & 20.13 \\
\hline Meat and Bone Meal & 1.12 & 5.00 & 5.00 \\
\hline Celite & 2.00 & 2.00 & 2.00 \\
\hline Animal and Vegetable Fat & 3.46 & 3.36 & 3.36 \\
\hline Limestone & 1.22 & 0.57 & 0.48 \\
\hline Dicalcium Phosphate & 1.51 & 0.51 & 0.45 \\
\hline DL Methionine & 0.36 & 0.32 & 0.22 \\
\hline L Lysine & 0.23 & 0.18 & 0.16 \\
\hline NB300 (PoultryVitamin Mineral Premix) & 0.25 & 0.25 & 0.25 \\
\hline Salt & 0.31 & 0.28 & 0.28 \\
\hline Sodium Bicarbonate & 0.20 & 0.11 & 0.06 \\
\hline L Threonine & 0.11 & 0.07 & 0.06 \\
\hline Coban or Chlorotetracycline & 0.025 & 0.05 & 0.05 \\
\hline Sand & 0.058 & 0.058 & 0.058 \\
\hline \multicolumn{4}{|c|}{ Calculated Nutrients } \\
\hline Net Energy(hcallib) & 3031 & 3096 & 3163 \\
\hline Crude Protein (\%) & 21.26 & 20.3 & 17.78 \\
\hline Dig Lysine $(\%)$ & 1.18 & 1.05 & 0.89 \\
\hline Dig Arginine (\%) & 1.26 & 1.13 & 0.96 \\
\hline Dig Isoleucine $(\%)$ & 0.85 & 0.78 & 0.68 \\
\hline Dig Methionine $(\%)$ & 0.63 & 0.58 & 0.46 \\
\hline Dig Meth + Cyst $(\%)$ & 0.91 & 0.83 & 0.69 \\
\hline Dig Threorine (\%) & 0.77 & 0.68 & 0.59 \\
\hline Dig Trypophan (\%) & 0.25 & 0.21 & 0.18 \\
\hline Dig Valine $(\%)$ & 0.94 & 0.89 & 0.79 \\
\hline Calcium $(\%)$ & 0.96 & 0.86 & 0.80 \\
\hline Available Phosphorus (\%) & 0.45 & 0.42 & 0.40 \\
\hline Sodium $(\%)$ & 0.20 & 0.19 & 0.18 \\
\hline
\end{tabular}

E. coli in poultry litter. The variable concentrations of $E$. coli in fresh litter collected from below the chicks (FW) and from litter incubated in-house for 1, 2, 3 or 4 weeks (i.e., W1, W2, W3, and W4) are shown in Figure 2.4. A steady increase in the concentration of E. coli in 
the first four fresh week (FW) samples as measured by culture based methods was observed from $4.47 \log \mathrm{MPN} \mathrm{g}^{-1}$ to $8.47 \log \mathrm{MPN} \mathrm{g}^{-1}$ (Figure 2.4A). A steady increase in concentration of $E$. coli in the litter under the chicks was observed after the first four weeks of age and then the concentration of $E$. coli stabilized. In contrast there was a decline in $E$. coli concentrations in the tubes that were incubated in the pens (Figure 2.4B-E). The concentration of E. coli declined in the tubes of litter separated from the chicks and it took approximately 7-15 days for E. coli to decay to concentrations where they were no longer detected by culture methods.

The concentration of $E$. coli measured by qPCR in the FW samples did increase over the course of the study, but the results were not correlated with the culture based results (Pearson's correlation, $\mathrm{p}=0.3$ ). In contrast to the culture methods, very high concentrations of $E$. coli were observed by qPCR methods, ranging from $8.11 \log$ gene copies $\mathrm{g}^{-1}$ to $10.70 \log$ gene copies $\mathrm{g}^{-1}$. No significant increase or decrease in the concentrations of $E$. coli was observed by qPCR methods. Variability in the qPCR results within a treatment are likely due to the small sample size taken into the DNA extraction (only $0.25 \mathrm{~g}$ ), the inherent heterogeneity in the litter sample and methodological error. 

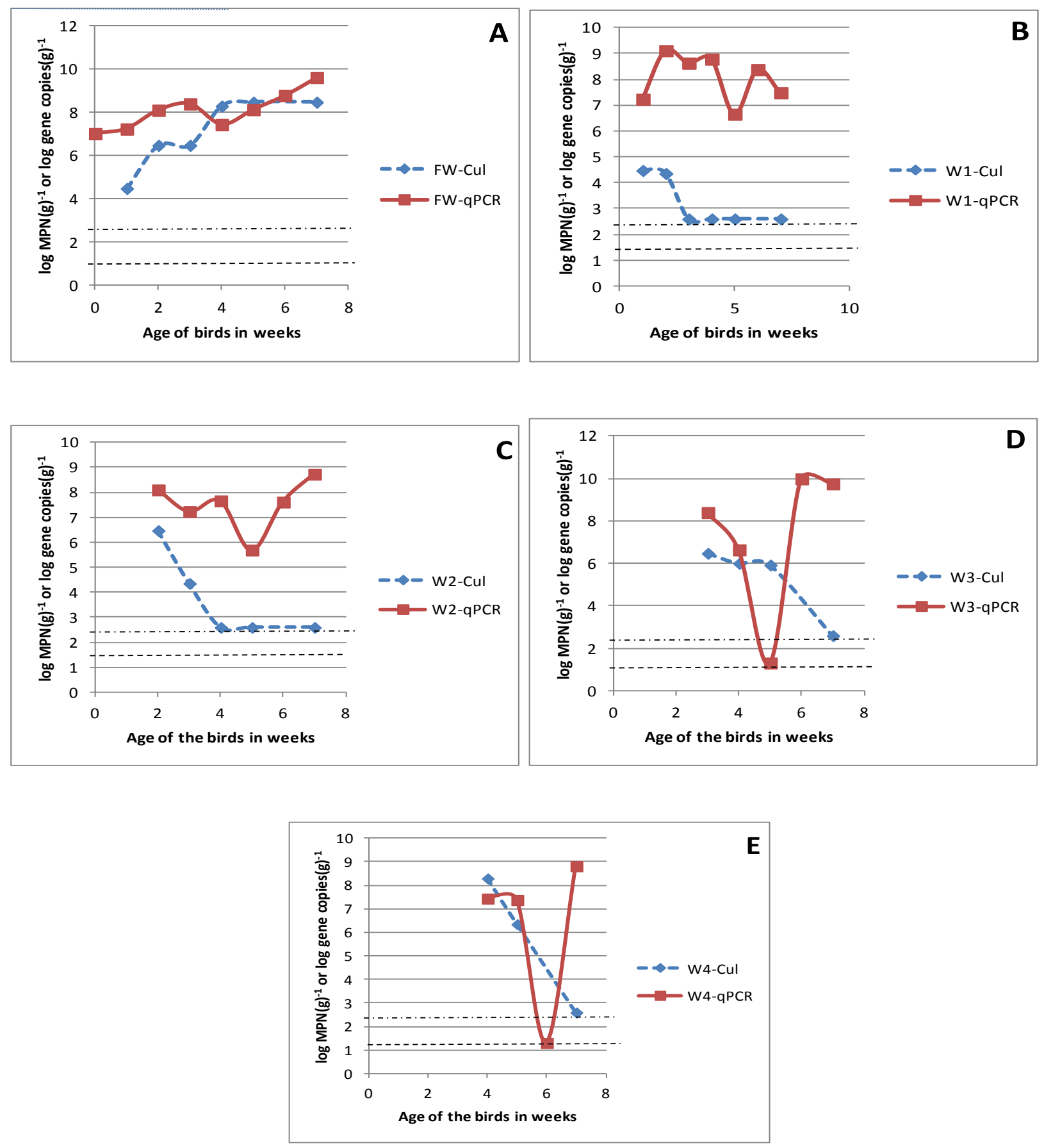

Figure 2.5 Concentration of E. coli observed by culture and qPCR methods in the poultry litter below the birds (FW) and in litter incubated in tubes in the pens (W1, W2, W3, W4). The horizontal dash-dot line indicates the minimum detection limit for the culture based methods and dashed line is for qPCR method.

Enterococcus sp. in poultry litter. The changes in concentrations of Enterococcus sp. over the period of seven weeks in fresh week samples and the tubes that were hung in pens are 
shown in the Figure 2.5. In this study the enterococci concentrations increased over time in fresh litter similar to E. coli (Figure 2.5). The concentrations of Enterococcus sp. increased from 4.47 to $8.47 \log \mathrm{MPN} \mathrm{g}^{-1}$ by culture-based methods. The final concentrations of both $E$. coli and Enterococcus sp. are same due to the number of dilutions carried out for analysis of both of them were same. The Thomas equation while calculating the concentrations takes into account the no of positive and negative plates in each dilution but the count of colonies. Hence we got the same concentrations for both the FIB (E. coli and Enterococcus sp.) observed in deposition study. The concentrations of W1 samples that were hung in tubes and collected in consecutive weeks initially increased and then decreased from 4.47 to $2.59 \log \mathrm{MPN} \mathrm{g}^{-1}$ respectively in over a period of seven weeks as measured by culture-based methods. The tubes with initial concentrations higher than $8.29 \log \mathrm{MPN} \mathrm{g}^{-1}$ i.e., week 4, 5, and 6 samples took more time to decay in the tubes and are shown in the Figure 2.5B.

Very high microbial DNA concentrations were detected by qPCR methods. Initial concentrations of FW samples were observed to increase from 9.54 to 10.13 log gene copies $\mathrm{g}^{-1}$ over seven weeks. No significant increase or decreases in concentrations were observed in Enterococcus sp. DNA when compared to the number of culturable Enterococci. There was a positive correlation $(\mathrm{n}=6, \mathrm{r}=0.99, \mathrm{p}<0.001)$ between the indicator bacteria $E$. coli and Enterococcus sp. detected by culture-based methods in the FW samples and incubated samples $(n=20, r=0.64, p=0.002)($ Figure 2.6). There was no correlation between the enterococci qPCR and culture based results in this study. 

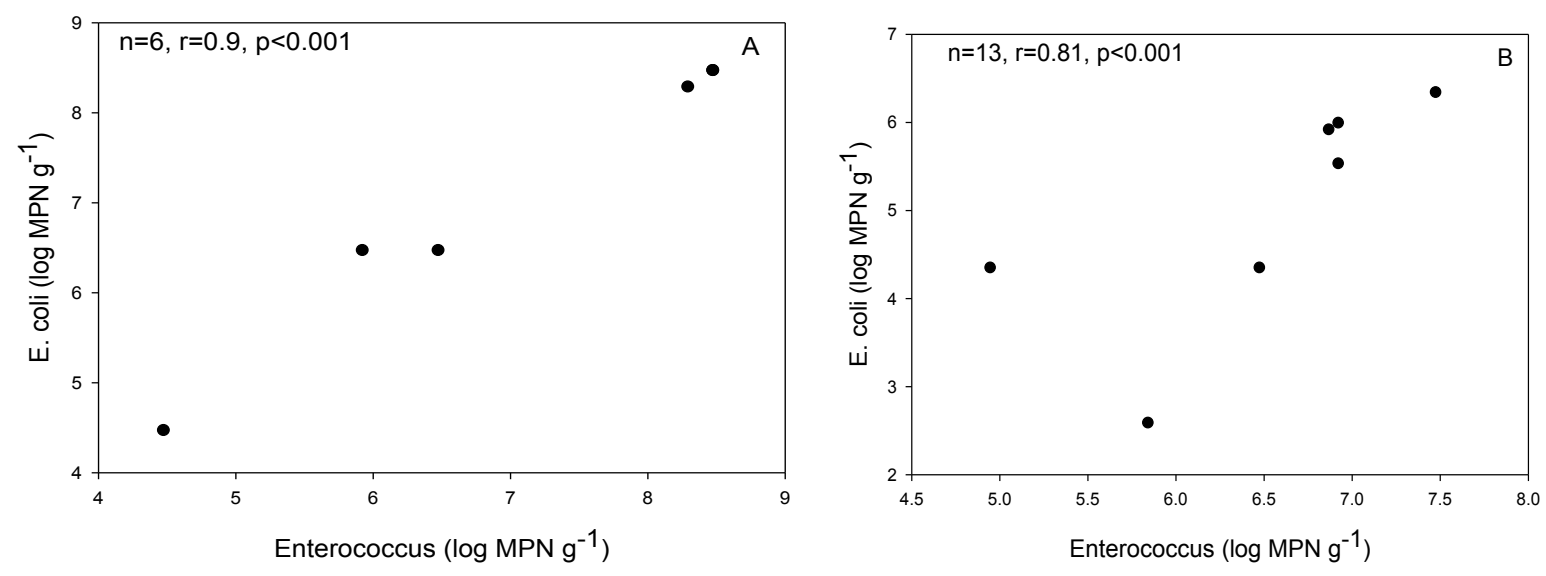

Figure 2.6 Correlation between E. coli and Enterococcus sp. present in the FW samples (A) and the incubated samples (B) tested by culture based methods. 

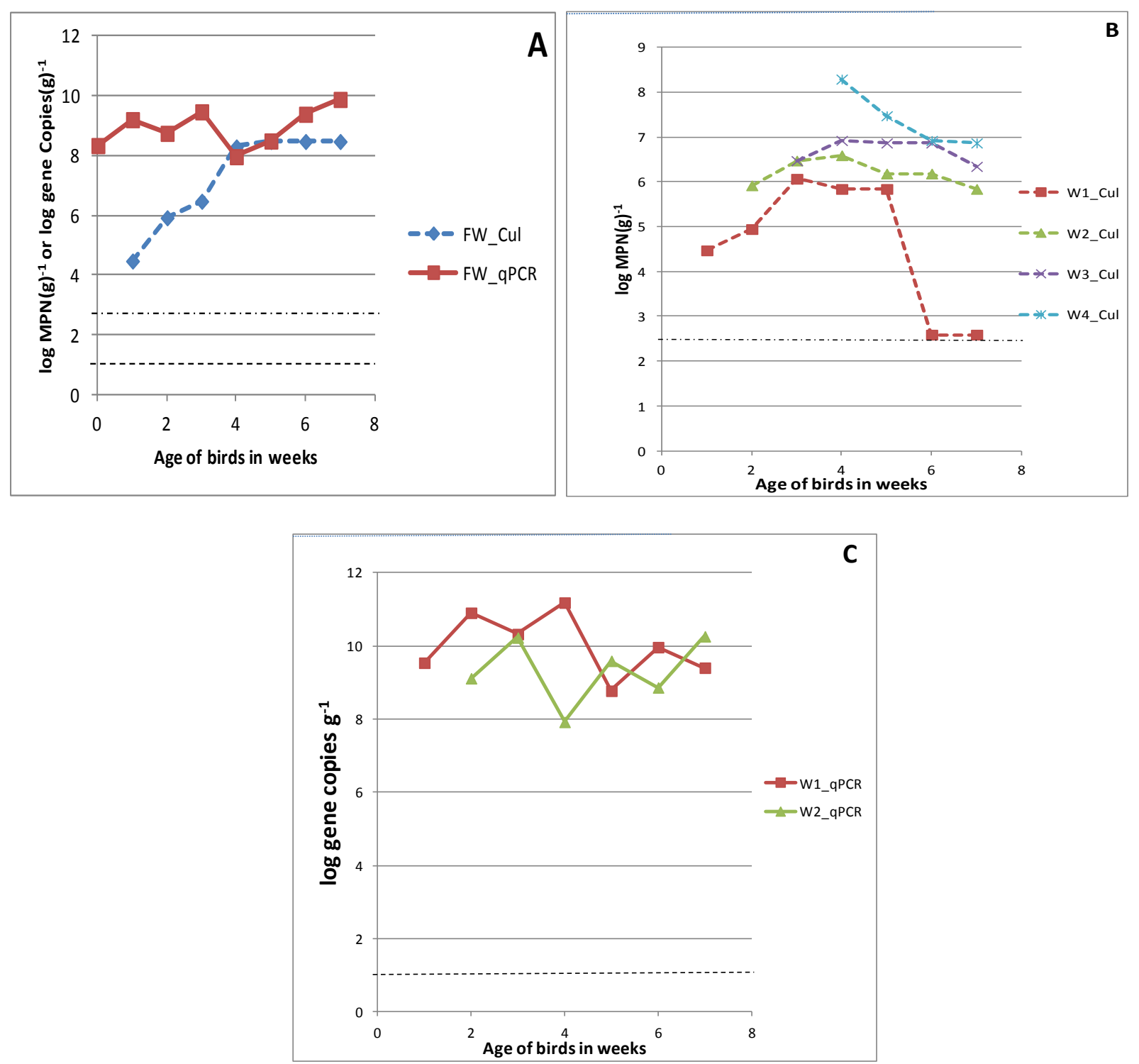

Figure 2.7 Concentrations of Enterococcus sp. by culture and qPCR methods. Poultry litter below the birds (FW) and in litter incubated in tubes in the pens (W1, W2, W3, W4). The dashed-dot lines at the bottom in the graphs were minimum detection limits of enterococci by Culture-based method and dashed line was by qPCR methods.

Staphylococcus sp. in poultry litter. All samples were tested for Staphylococcus sp. using culture-based and qPCR methods and the graphs were presented in Figure 2.6 (A and B). Staphylococcus aureus was not detected by the qPCR assay, hence only culture based results are reported. The culture-based method used in this study is specific to Staphylococcus sp. whereas 
qPCR tests for $S$. aureus which is a pathogen. Testing of the Staphylococcus sp. detected in culture-based methods for the S. aureus 16S rRNA targeting sec gene indicated this organism was not detectable by qPCR in our samples. The initial concentration of Staphylococcus sp. in poultry litter was observed to be increased from 4.3 to $8.77 \log \mathrm{MPN} \mathrm{g}^{-1}$ over seven weeks, similar to the observations for E. coli and Enterococcus sp. The increase in concentrations were observed with the increase in age of birds and doubled in concentrations as in E. coli by the end of week 7. In the incubated samples that were hung in tubes it was observed that the Staphylococcus sp. decreased over a period of time, but the rate of decrease was less than that observed for E. coli. The increase in Staphylococcus sp. in FW samples positively correlated with increase in E. coli $(\mathrm{n}=7, \mathrm{r}=0.99, \mathrm{p}<0.001)$, and Enterococcus $\mathrm{sp} .(\mathrm{n}=7, \mathrm{r}=0.9, \mathrm{p}<$ $0.001)$ by culture based methods.
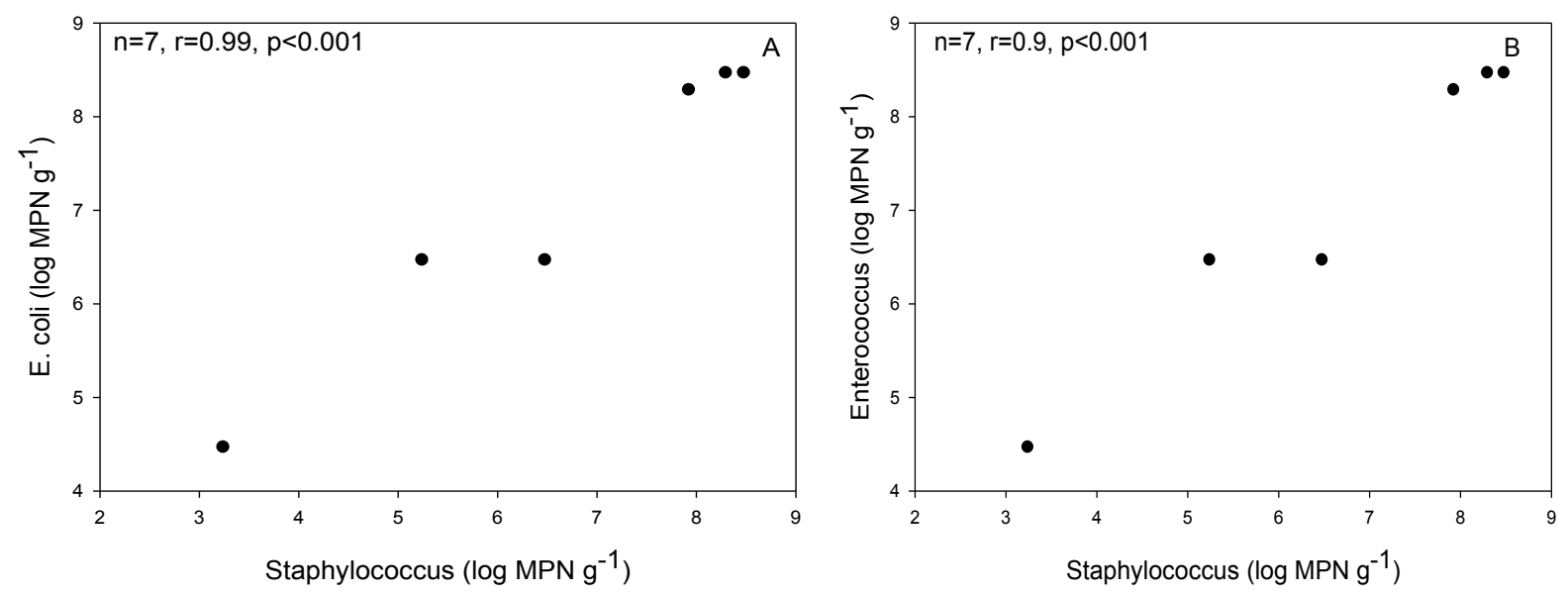

Figure 2.8 Correlation of Staphylococcus sp. with E. coli (A) and Enterococcus sp. (B) in FW by culture based methods. 

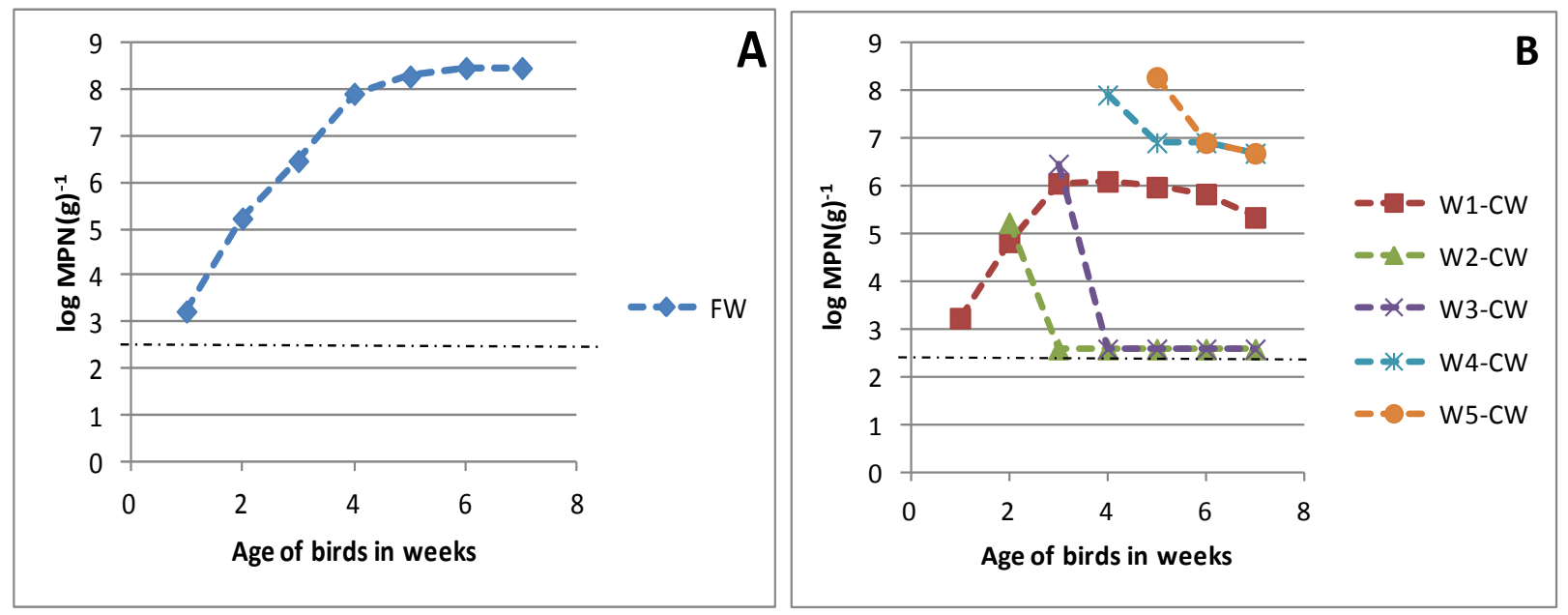

Figure 2.9 Concentrations of Staphylococcus by culture methods. Poultry litter below the birds (FW) and in litter incubated in tubes in the pens (W1, W2, W3, W4). The straight dashed-dot line at the bottom represents minimum detection limits for culture based methods.

Bacteroidales in poultry litter. All the samples were investigated for Bacteroidales by qPCR assays and the graphs are presented in Figure 2.7. No significant or decrease was observed in the concentrations of fresh week samples. It is likely the drop in concentration observed by both qPCR and culture based methods in the FW samples collected in week 5 are an artifact of sample collection or handling rather than a real decrease in Bacteroidales concentrations. Concentrations ranged from $6 \pm 0.5 \log$ gene copies $\mathrm{g}^{-1}$ over a period of 7 weeks not including week 5. As we know the qPCR detects dead cells and the Bacteroidales were detected in the initial clean wood shavings that were collected in the poultry farm we would expect them to be present in all the samples that were tested in this study. Bacteroidales were observed to be present in higher concentrations compared to other microbial concentrations in the initial 4 weeks. No significant trends can be observed in the Bacteroidales concentrations from the incubated tube samples based on qPCR results due to variability in the data. This variability in the qPCR results is thought to be due to sampling error during sample homogenization, the small 
volume taken into the DNA extractions, the heterogeneity of microorganisms in the litter samples even after mixing. No significant correlation was observed with any other microorganisms present in poultry litter evaluated in this study.
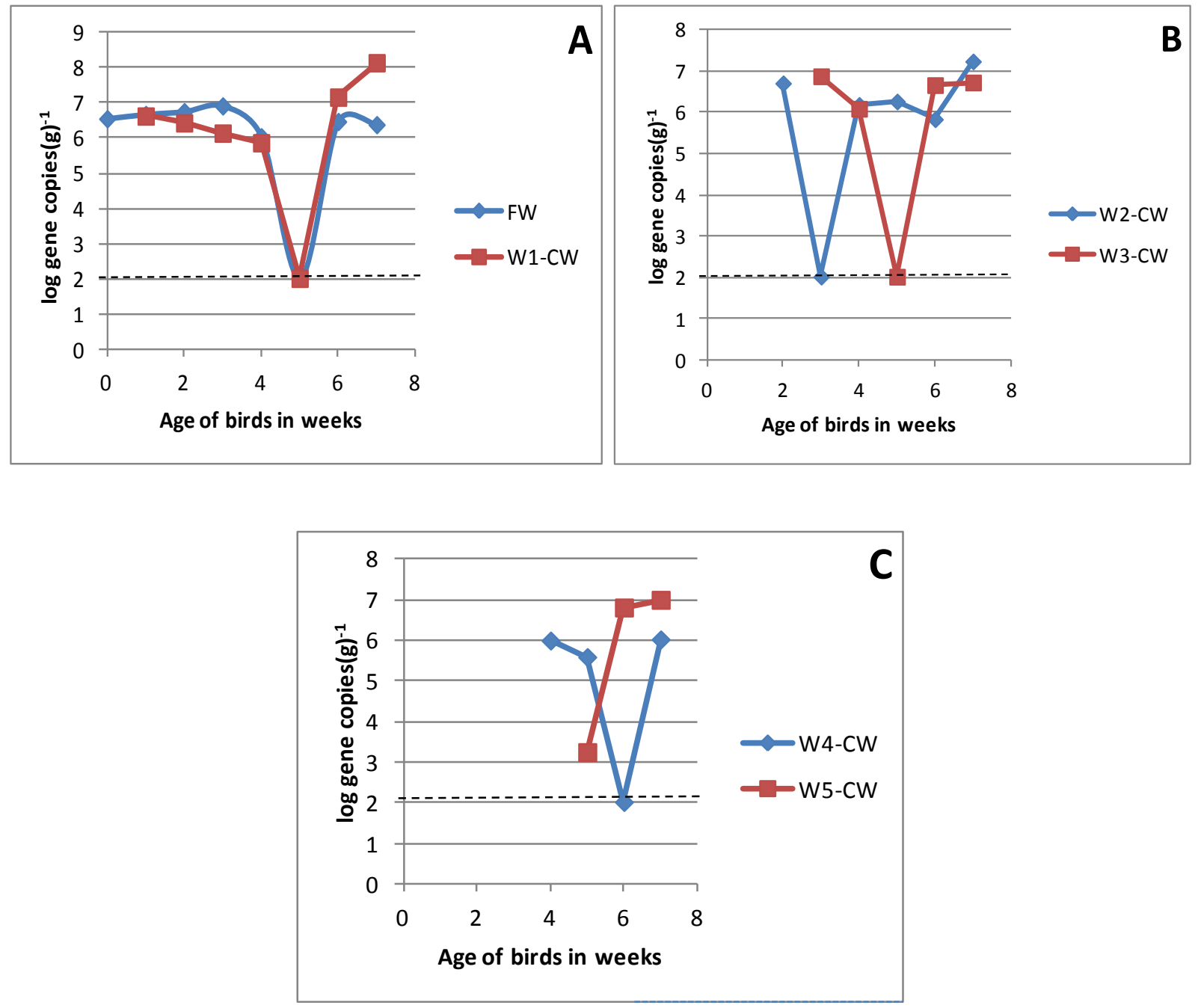

Figure 2.10 Concentrations of Bacteroidales by qPCR methods. Poultry litter below the birds (FW) and in litter incubated in tubes in the pens (W1, W2, W3, W4). The dashed straight lines at the bottom represent the minimum detection limits of the samples for Bacteriodales $\mathrm{qPCR}$ method.

Brevibacterium sp. LA35 in poultry litter. All the samples were tested for LA35 and their concentrations were presented in the Figure 2.8 (A, B and C). It was first detected in week 
2 at $3.9 \log$ gene copies $\mathrm{g}^{-1}$ was not detected by qPCR again in poultry litter until the birds are 5 weeks old. The early detection of LA35 in week two may be due the heterogeneity of the litter and collection of a larger mass of chicken feces in that sampling event compared to the other sampling events. The week 5 through 7 fresh week samples were observed to be increase from 1.02 to $5.0 \log$ gene copies $\mathrm{g}^{-1}$. Non-detect concentrations were set to half the maximum detection limit and were represented by dashed lines in the graphs. Among the samples that were hung in tubes most did not contain detectable concentrations of LA35 by qPCR. Only the Week 4 sample that was collected on Week 5 contained concentrations of LA35 at $2.05 \log$ gene copies $\mathrm{g}^{-1}$. 

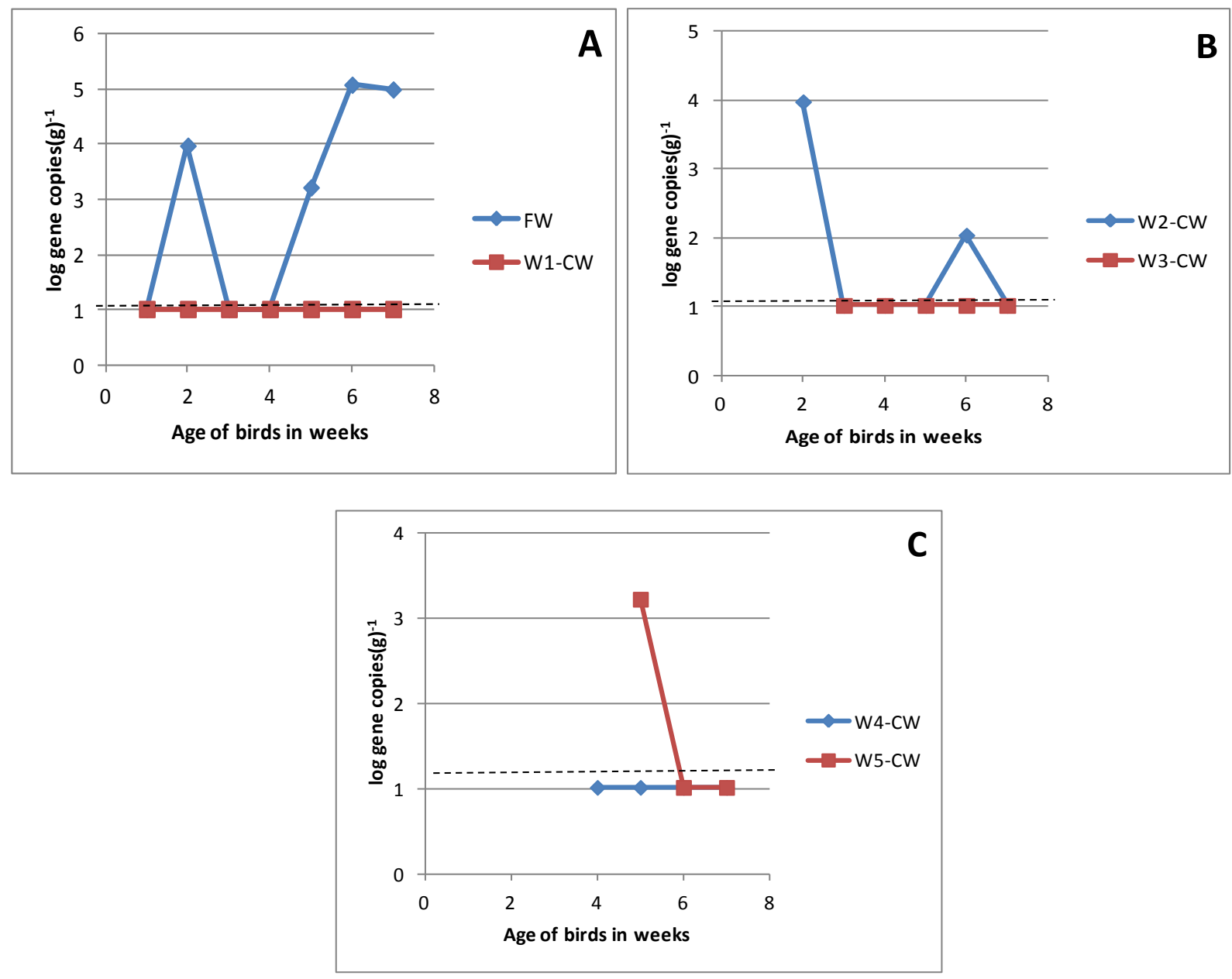

Figure 2.11 Concentrations of Brevibacterium sp. in poultry litter by qPCR methods. Poultry litter below the birds (FW) and in litter incubated in tubes in the pens (W1, W2, W3, W4)

Salmonella sp. in poultry litter. Salmonella sp. were not detected in any of the samples collected for the deposition study by both culture-based and qPCR methods. The pens had been cleaned with the disinfectant (Virocid, CID Lines, Belgium, Europe) immediately prior to placing fresh wood shavings and new chicks on the bedding. This cleaning was conducted to eliminate systemic Salmonella in the flock at the WVU animal sciences farm. This cleaning process likely removed any Salmonella sp. from the pens and prevented infection of the new flock. 


\section{SOIL COLUMN STUDY}

The overall goal of this study was to evaluate the release and transport of the pathogen (S. Typhirium), FIB (Enterococcus sp., and E. coli) and MST markers (LA35 and Bacteroidales) from poultry litter under a simulated rainfall event through loamy-sand or sand columns. A constant flow of DI water was applied to the top of the soil columns and the leachate was collected at regular time periods over 2 hours. The transport and attenuation of microorganisms through (1) an acid washed sand column and (2) replicate loamy sand columns was observed for 10 to 30 pore volumes. The microbial concentrations in leachate and soil were determined by qPCR.

\subsection{Materials and methods}

The section below details the materials and methods used for the soil column studies. The general research flow is shown in Figure 3.1 and the laboratory soil column setup is shown in

Figure 3.2.

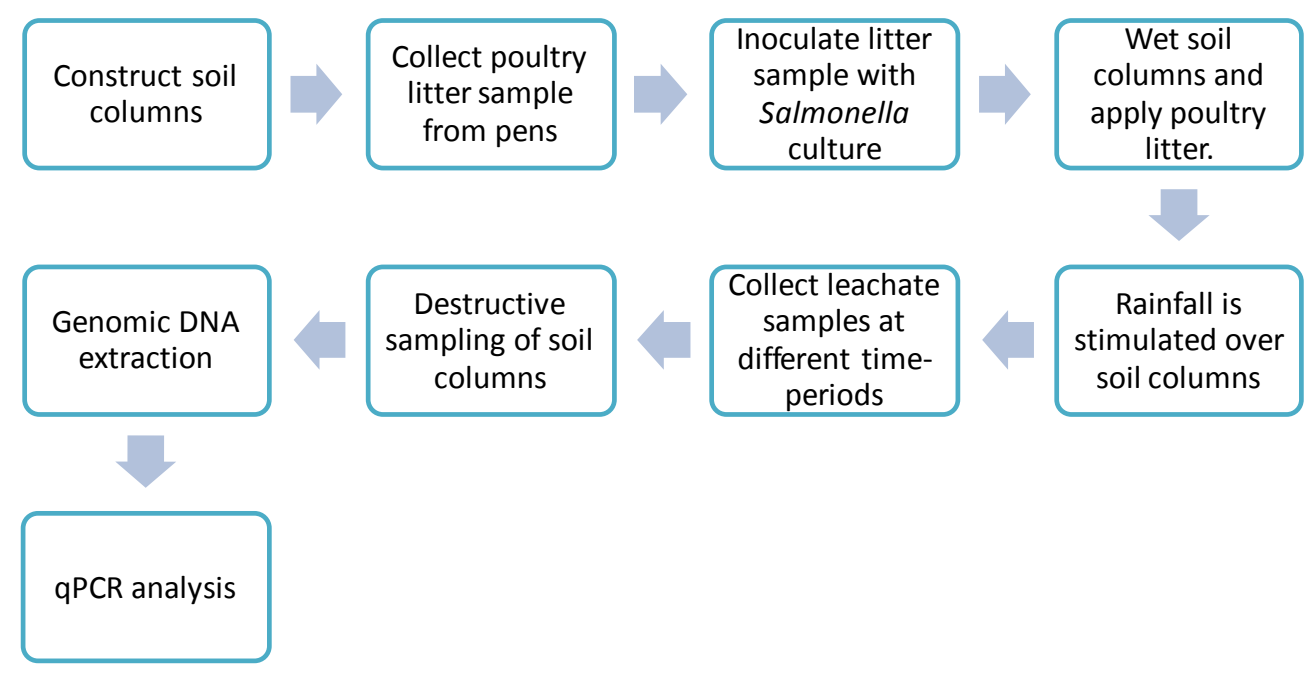

Figure 3.1 Schematic diagram of soil column study. 


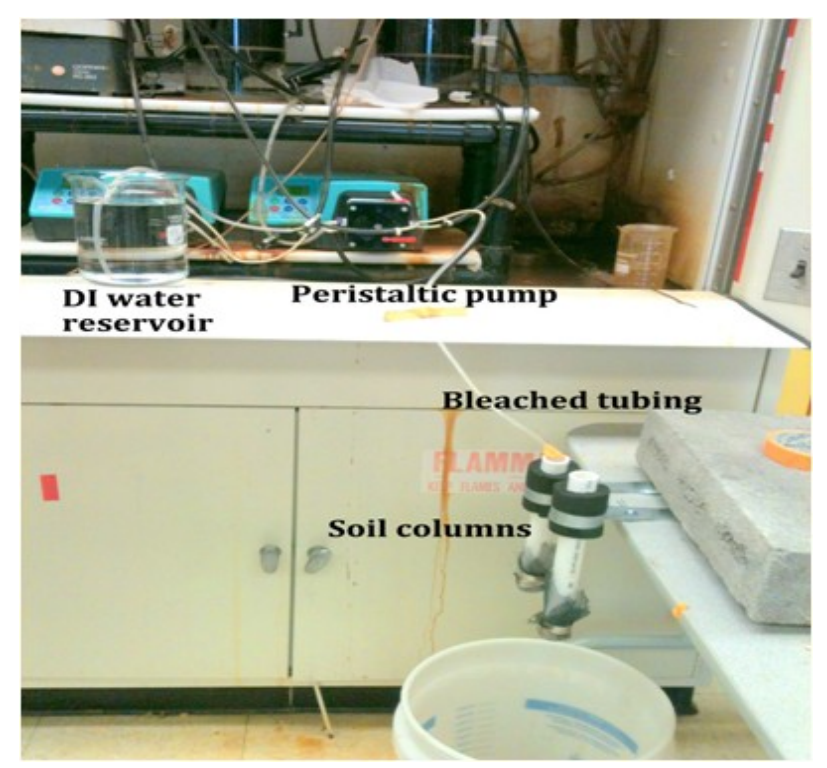

Figure 3.2 Soil column experiment setup in laboratory

\subsubsection{Determining the properties of sand and loamy-sand.}

Sieve analysis. A total of $500 \mathrm{~g}$ each of acid washed sand and oven dried loamy-sand samples were sieved using an electric shaker for a period of 5 min to determine the average percent of sand and percent of silt and clay. This experiment was repeated twice and average values were recorded.

Organic matter test. Approximately 5 to $7 \mathrm{~g}$ of both an acid washed autoclaved sand sample and an oven dried loamy-sand sample was taken into pre-weighed crucibles and oven dried at $105^{\circ} \mathrm{C}$ for 2 hours and the weight was recorded to $\pm 0.001 \mathrm{~g}$. The samples are again heated for 2 hours at $360{ }^{\circ} \mathrm{C}$ and then cooled in a desiccator. The sample is weighed in a draft free environment to $0.001 \mathrm{~g}$. This drying at $360^{\circ} \mathrm{C}$ is repeated twice. The loss on ignition (LOI) is calculated using Equation 4. 


$$
\text { LOI }(\%)=\frac{\text { Weight at } 105^{\circ} \mathrm{C}-\text { Weight at } 360^{\circ} \mathrm{C}}{\text { Weight at } 105^{\circ} \mathrm{C}} \times 100
$$

Equation 4

\subsubsection{Sand acid-wash procedure}

The sand used in the soil column was acid washed to remove organic material prior to its use. This was performed according to the method proposed by Bolster et al., 2012. Sakrete natural play sand (Bonsal American, Inc. USA) was used. The sand was sifted through 250 um sieve (USA standard testing sieves, ATM corp., New Berlin, WI.) and then boiled in a 2-L conical flask containing $1 \mathrm{~mol} \mathrm{~L}^{-1}$ hydrochloric acid (Fischer Scientific, Pittsburgh, PA) for 2 hours and then rinsed with DI water until the rinse water had a $\mathrm{pH}$ of 5.6. An Orion ROSS pH electrode (Thermo Scientific, Waltham, MA) was used to measure solution $\mathrm{pH}$. The sand was then dried in an oven (Thermo Scientific Furnace, USA) at $105^{\circ} \mathrm{C}$ overnight. The oven-dried sand is again re-rinsed in DI water the following day and dried again overnight in an oven. Finally, the sand was sterilized by autoclaving at $121^{\circ} \mathrm{C}$ for $15 \mathrm{~min}$. The sterile sand was then allowed to cool room temperature and transferred aseptically into soil columns using a sterile spatula before conducting the experiment.

\subsubsection{Sample Collection}

The poultry litter samples were collected from the WVU Animal Sciences Farm (Morgantown, WV). Approximately 6 scoops (ca. 5 g) of poultry litter were collected from random locations within a $2.1 \times 1.3 \mathrm{~m}^{2}$ area containing soiled poultry bedding (i.e., fecally contaminated wood shavings). Samples for the sand column study were taken from pens containing adult roosters. Whereas the soiled poultry litter for loamy-sand column studies were collected from pens containing female chickens aged 4 to 6 weeks. Random sampling locations 
were biased towards wet litter to ensure sufficient quantities of microorganisms. The poultry litter was homogenized in the field in a sterile, stainless steel bowl by mixing with a sterile spoon. Loose feathers and large particles of wood shavings were removed. Homogenized samples of approximately $5 \mathrm{~g}$ were transferred into a sterile whirl pak bag (Nasco, ISO: 9001, Fort Atkinson, WI). Poultry litter samples were held on ice after collection and during transport to the laboratory. All DNA extractions were done on the same day of sample collection. All samples were held on ice for no longer than 3 hours prior to adding them to soil columns.

\subsubsection{Growth and maintenance of $S$. Typhirium cultures}

Salmonella sp. invA gene was not detectable by qPCR in the poultry litter collected for these studies (as reported in section 2.2). Therefore, $7.54 \mathrm{log}$ gene copies $\mathrm{g}^{-1}$ of Salmonella enterica serovar typhirium (ATCC 14028) were mixed into approximately $1.685 \mathrm{~g}$ of poultry litter prior to the addition of the poultry litter to the top of the soil columns. The concentration of S. Typhirium was determined by qPCR of approximately $0.25 \mathrm{~g}$ of poultry litter sample inoculated with S. Typhirium cultures prior to setting up the soil column experiment. The inoculum of S. Typhirium culture was maintained on XLT4 (Difco ${ }^{\mathrm{TM}}$, MD, USA) agar slants. Prior to inoculation into poultry litter, S. Typhirium was enriched on $240 \mathrm{~mL}$ of selective RVbroth (Rappaport-Vassiliadis Oxoid, CMO669, Pittsburgh, PA). RV-broth was prepared according to manufacturer's instructions. S. Typhirium was incubated at $37^{\circ} \mathrm{C}$ at $200 \mathrm{rpm}$ (Fisher scientific shaker, New Brunswick, NJ. ) for 2 to 3 days or until the broth turned turbid. The turbid cultures were taken in six sterile centrifuge tubes of $40 \mathrm{~mL}$ each and centrifuged (Avanti J-E, Beckman Coulter, USA) at 10,000 rpm for $10 \mathrm{~min}$ at $17^{\circ} \mathrm{C}$. Supernatant was removed by pipette and the wet solid residue was aseptically added to approximately $1.5 \mathrm{~g}$ of 
poultry litter in sterile stainless steel bowl and homogenized by mixing with a sterile spoon. This S. Typhirium spiked poultry litter was immediately used in the sand and loamy-sand-sand column studies.

\subsubsection{Soil columns preparation}

The release and transport of pathogens and FIB from poultry litter were observed in two different types of soil columns: (1) acid washed, sterilized sand and (2) a mixture of $30 \%$ sterilized loamy-sand and 70\% acid washed sterilized sand. For the loamy-sand soil column study, loamy-sand was collected from the surroundings of WVU campus and heated at $100{ }^{\circ} \mathrm{C}$ overnight to remove moisture, and sieved through a $2 \mathrm{~mm}$ sieve (USA standard testing sieves, Size 10, ASTM, New Berlin, WI). This soil was then sterilized by autoclave once at $121{ }^{\circ} \mathrm{C}$ for 15 min. The column consisted of a $15 \mathrm{~cm}$ long $\mathrm{x} 2 \mathrm{~cm}$ diameter PVC cylinder. The bottom of the PVC column was closed using glass fiber wool (Fischer scientific, Pittsburgh, PA) to retain soil while permitting the flow of water and microorganisms. The glass fiber wool was kept at the bottom of the column with a steel wire mesh and tightened with a steel screw and nut. The column was then filled with the soil selected for that treatment up to a depth of $12 \mathrm{~cm}$ and topped with approximately $1.685 \mathrm{~g}$ of homogenized poultry litter spiked with S. Typhirium cultures. The soil columns were then completely saturated by placing the soil column vertically into a bucket containing DI water but not submerged. Soil pore spaces were filled with water from the bottom to top by this immersion method typically within $15-20$ min as evidenced by wetting of the top of the soil. This soil column was then carefully transported by hand to the experiment setup area and was connected to the peristaltic pump (Watson Marlow, Wilmington, MA). 


\subsubsection{Electrical conductivity test}

A standard $1 \mathrm{M} \mathrm{NaCl}$ solution is prepared by adding $58.44 \mathrm{~g}$ of molecular grade $\mathrm{NaCl}$

(Fisher Scientific, Pittsburgh, PA) into 1 L of sterile DI water. Electrical conductivity of standard aqueous $1 \mathrm{M} \mathrm{NaCl}$ solution at $21.1^{\circ} \mathrm{C}$ was measured as $1.84 \alpha$ using a conductivity meter (Hach, CO 150, USA.). A total of $50 \mathrm{~mL}$ of standard aqueous $1 \mathrm{M} \mathrm{NaCl}$ solution diluted in DI water was slowly poured onto a soil column previously saturated with water by hand. This was followed by $50 \mathrm{ml}$ of sterile DI water applied by hand for a time-period of $5 \mathrm{~min}$. The column effluent outflow was collected in a different sterile glass jar every $1.0 \mathrm{~min}$. Electrical conductivity measurements were taken at a regular time intervals (ea. $0.5 \mathrm{~min}$ ) using a conductivity meter in a sterile glass jar which was rinsed with $10 \%$ bleach between each sampling event. All the readings were recorded in $\mathrm{mS}$ units by dropping the conductivity meter into the sterile glass jar immediately after sample collection and the reading were recorded over $10-15 \mathrm{sec}$

\subsubsection{Soil column study assay}

Porosity. The porosity of the soil columns was measured using the water displacement method. A cleaned sterile graduate cylinder is filled with sterile DI water, and an empty bleached (10 \% bleach) PVC column which was to be used for soil column experiment is submerged into the water in the graduate cylinder. The change in water level was recorded to determine the volume of the PVC column material. Then the empty PVC column is packed with the treatment soil, and the PVC and soil column is again submerged into graduate cylinder containing sterile DI water. Some standing time is allowed to slowly fill the pore volumes with water and displace air in the soil voids. The change in water volume was recorded after the sand was observed to be 
wet at the top of the column. Porosity was calculated based on the difference in volumes of water displaced between the empty PVC column and the packed PVC column. Porosity was determined just before starting the soil column experiments.

Experiment setup. A total of $1.685 \mathrm{~g}$ of homogenized freshly collected poultry litter was inoculated with S. Typhirium culture, added to the top of the constructed columns. A total of 50 $\mathrm{mL}$ of $10 \%$ bleach solution was passed through the tubes to sterilize the tubing from the pumps to the DI water reservoir. After sterilization one end of the pipe tubing was connected to the sterile jar containing $500 \mathrm{~mL}$ of DI water used to simulate rain water and the other end was connected to the soil column. The peristaltic pump was set at 30 RPM and delivered $16.4 \mathrm{~L} \mathrm{day}^{-1}$ to the top of the soil columns. All the experiments were conducted for approximately 2 hours. A total of 30 pore volumes of leachate was collected in the sand column study and 5 and 10 pore volumes of leachate was collected in the loamy-sand column replicates. The leachate through the soil column was collected in sterile centrifuge bottles $(60 \mathrm{~mL})$. The total of 11 to 13 samples consisting of 30 to $40 \mathrm{ml}$ of leachate were collected every 10 to $14 \mathrm{~min}$. All the samples collected during the experiment were held on ice and were centrifuged (Avanti J-E, Beckman Coulter, USA) at $10,000 \mathrm{rpm}$ for $10 \mathrm{~min}$ at $17^{\circ} \mathrm{C}$ within two hours of collection. The supernatant was carefully discarded and the cell and soil debris pellet was retained. Then the tubes were washed with $0.5 \mathrm{~mL}$ of sterile $1 \mathrm{X}$ PBS to collect the DNA adsorbed on to the sides of the centrifuge tube. A total volume of $0.5 \mathrm{~mL}$ of cells and soil debris from the centrifuged sample was taken into DNA extraction. 


\subsubsection{Soil sampling procedure}

Destructive sampling of the soil in the soil columns was done immediately after the cessation of gravity flow from the columns. All the soil columns used in the study were segregated into different sections on autoclaved, sterile aluminum foil (Figure 3.3). Soils were segregated by removing the glass fiber wool, and inverting and tapping vertically from top to bottom to push the soil onto the sterile foil. Soil sections were marked in serial order from top to bottom as the soil emerged from the PVC column. Sections were recombined in order and the separated into 3 equal length layers from top to bottom. The three separate layers were then homogenized independently using a sterile spatula and approximately $0.25 \mathrm{~g}$ of soil subsample was taken into the DNA extractions. Also DNA was extracted from both soil types (ea. $0.25 \mathrm{~g})$ prior to setting up the soil column experiment to determine if there were any microorganisms native to the soils after autoclaving that were detectable by qPCR. These samples were investigated for the presence of E. coli, Enterococcus sp., Bacteroidales, Salmonella Typhirium and Brevibacterium sp. LA35 according the methods in Table 2.3. 


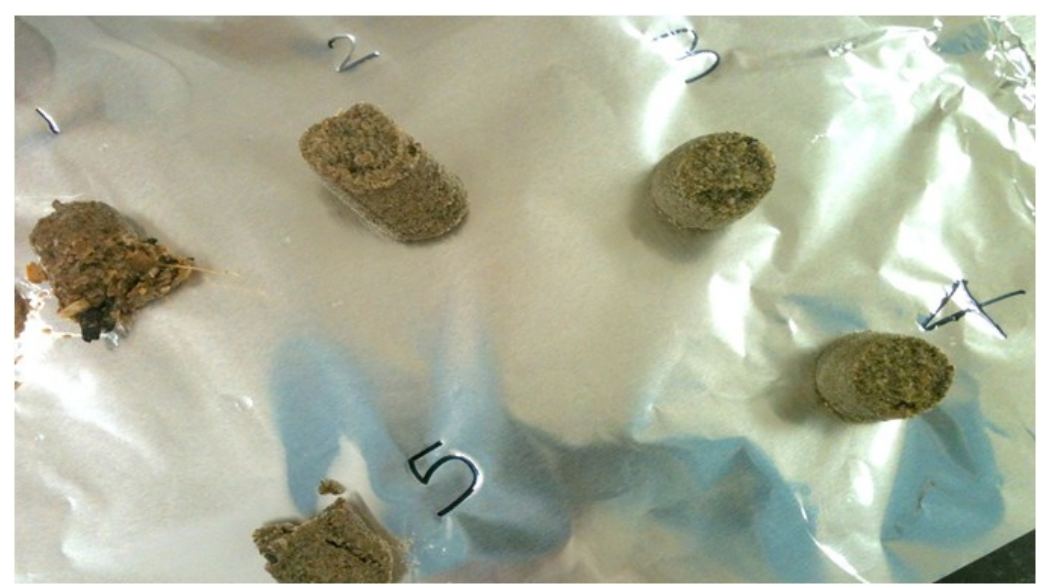

Figure 3.3 Example soil sections after removal from the PVC column with 1 representing the top of the column and containing litter and 5 representing the bottom of the column.

\subsection{Genomic DNA extraction method}

The DNA from all the samples was extracted using the DNA extraction method proposed by Griffiths et al., 2000. All the leachate samples were centrifuged at 10,000 rpm for $10 \mathrm{~min}$ and the supernatant was removed by pipette. The resulting pellet was diluted in $0.5 \mathrm{ml}$ of $1 \mathrm{X}$ sterile PBS. A total of $0.5 \mathrm{~mL}$ of the centrifuged samples and approximately $0.25 \mathrm{~g}$ of soil samples were placed into a FP 120 bead system tube (MP Biomedicals, Solon, OH). Then $0.5 \mathrm{~mL}$ of CTAB (cetyltrimethyl ammonium bromide) mixture and $0.5 \mathrm{~mL}$ of phenol: chloroform: isoamyl alcohol (25:24:1) (Fisher Biotech, Wembley, WA) was added to the tube. The CTAB mixture was $10 \%$ weight per volume CTAB (Sigma Life Sciences, St. Louis, MO) with $0.7 \mathrm{M} \mathrm{NaCl}$ (Fisher Scientific, Fair Lawn, NJ) and equal volume of $0.24 \mathrm{M}$ potassium phosphate (Fisher Scientific, Fair Lawn, NJ) at $\mathrm{pH}$ 8. The tube was vortexed for ten minutes at a setting of 8 in a horizontal position, and then spun at $4{ }^{\circ} \mathrm{C}, 16,000 \mathrm{x}$ g for five minutes in an Accuspin micro 17 R centrifuge (Fisher Scientific, Asheville, NC). The aqueous phase was transferred to a new, sterile $1.5 \mathrm{~mL}$ tube and the same volume of chloroform: isoamyl alcohol (24:1) (Sigma Life 
Sciences, St. Louis, MO) was then added. The tube was spun again for five minutes at $4{ }^{\circ} \mathrm{C}$, $16,000 \mathrm{x}$ g. The aqueous layer was again taken into a new, sterile $1.5 \mathrm{~mL}$ tube and 2 volumes of PEG (Polyethylene glycol) solution is added. The PEG solution was made with 30\% weight per volume PEG-6000 (Alfa Aesar, Ward Hill, MA) and 1.6M NaCl. The tube was then incubated in the dark at room temperature for two hours. Following incubation, the tube was spun at $4{ }^{\circ} \mathrm{C}$, $17,000 \mathrm{x} g$ for 15 minutes. The supernatant was removed by pipette, and then $100 \mathrm{uL}$ of ice cold $70 \%$ molecular grade ethanol (Sigma Life Sciences, St. Louis, MO) was added. The tube was spun for a final time at $4{ }^{\circ} \mathrm{C}, 17,000 \mathrm{x}$ f for 15 minutes. The ethanol was removed with a pipette and then placed in the hood to evaporate any remaining ethanol. The DNA was eluded in 10 $\mathrm{mM}$ Tris (Ambion, Grand Island, NY) with a final volume of $25 \mathrm{uL}$. Concentrations of DNA were determined by absorbance at $260 \mathrm{~nm}$ with Nanodrop ND-1000 UV Spectrometer (Nanodrop Technologies, Wilmington, DE).

\subsection{Taqman qPCR assay}

The Taqman qPCR assays to quantify microorganism in the leachate and soil samples were performed according to the methods described in Section 2.5.

\subsection{Results}

Soil characterization. An average of $87.8 \%$ sand and $12 \%$ of silt and clay before blending soils was present in the oven dried loamy-sand soil sample, whereas acid washed and autoclaved sand sample consists of $96.8 \%$ of sand and $3.4 \%$ silt and clay. Based on LOI analysis, the acid washed and autoclaved sand sample consisted of $0.098 \%$ of organic matter compared to $0.97 \%$ of organic matter in oven dried loamy-sand soil sample before blending of the soil. Different sieves used for this experiment and the particles each sieve allow to pass are 
shown in Table 3.1. Based on the soil textural triangle the loamy-sand sample can be classified as loamy sand and the sand sample can be classified as sand.

Table 3.1 Different sieves used for sieving and the size of particles retained on them

\begin{tabular}{|c|c|}
\hline ASTM sieve no & $\begin{array}{l}\text { Grain size } \\
\text { retained in } \\
\text { mm }\end{array}$ \\
\hline 10 & 2 \\
\hline 40 & 0.42 \\
\hline 100 & 0.106 \\
\hline 140 & 0.074 \\
\hline 200 & 0 \\
\hline Pan
\end{tabular}

Microorganisms were not detectable by qPCR analysis in neither the autoclaved $30 \%$ loamy-sand soil sample nor the acid washed autoclaved sand sample used to construct the soil columns. Nanodrop concentrations of DNA for these samples were $0.1 \mathrm{ng} / \mathrm{uL}$ and $0.3 \mathrm{ng} / \mathrm{uL}$ for sand and loamy-sand soil columns, respectively.

\subsubsection{Tracer breakthrough curve.}

Electrical conductivity was measured to determine breakthrough in the soil columns of a conservative tracer. Electrical conductivity of a $1 \mathrm{M}$ standard $\mathrm{NaCl}$ solution in DI water and sterile DI water was observed to be $77.7 \mathrm{mS}$ and $0.0146 \mathrm{mS}$, respectively. The variation of EC in the leachate from the saturated sand column is shown in the Figure 3.4. The highest EC readings were observed to be $78.4 \mathrm{mS}$ at 1.22 pore volumes in $5 \mathrm{~min}$. The breakthrough of the 
conservative tracer suggests an overestimation of the soil pore volume by the column submersion method compared to the electrical conductivity test.

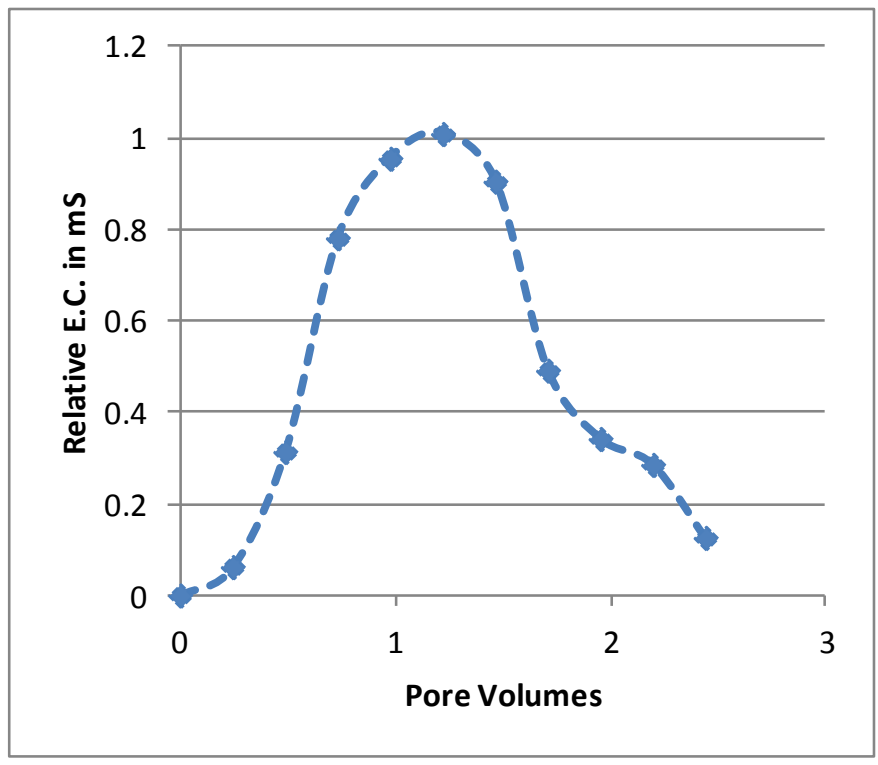

Figure 3.4 Electrical Conductivity of $1 \mathrm{M} \mathrm{NaCl}$ solution in Sand column

\subsubsection{Microbial concentrations in poultry litter.}

The initial microbial concentrations in poultry litter used in the soil column study before conducting the experiment are shown in the Figure 3.5. In general the poultry litter collected for the sand column has the highest microbial concentrations compared to the microbial concentrations in the poultry litter collected for loamy-sand soil column and replicate soil column studies. The concentrations of S. Typhirium were always higher compared to other microbial concentrations as the poultry litter was spiked with $S$. Typhirium cultures grown in laboratory. 


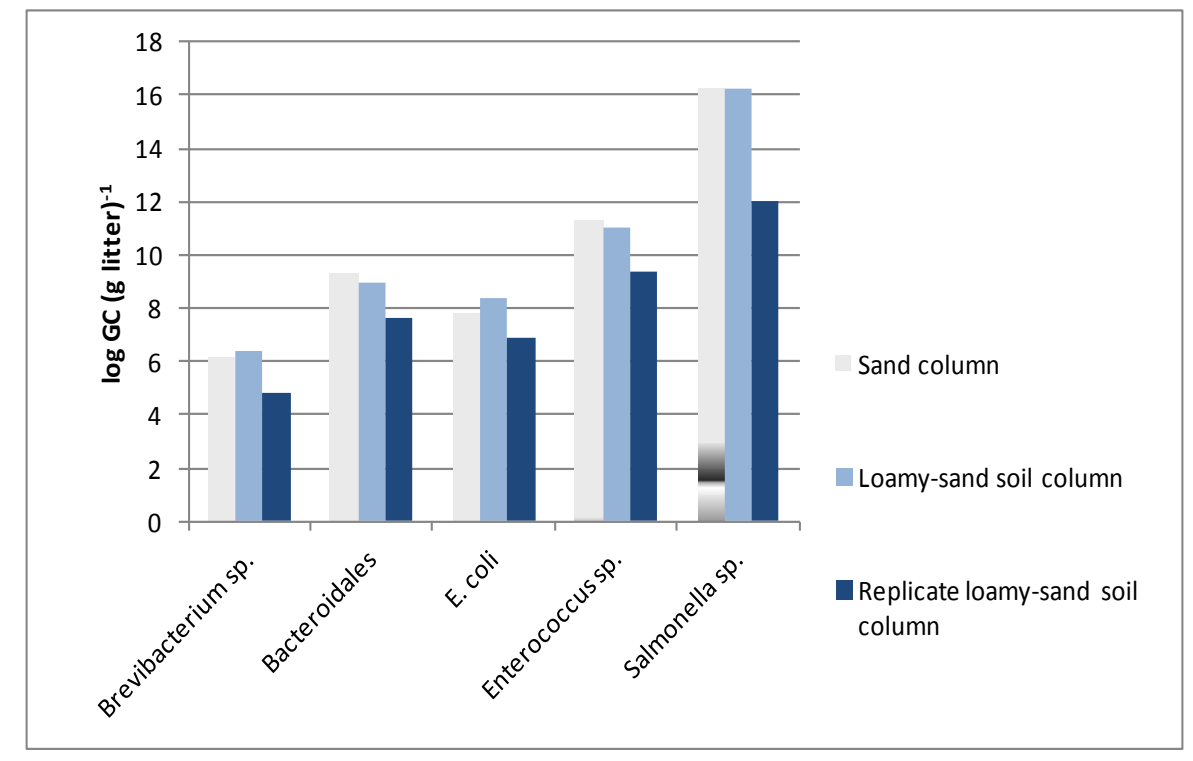

Figure 3.5 Initial microbial concentrations in poultry litter used in the soil column studies

\subsubsection{Microbial concentrations in the leachate from the soil columns.}

The porosity of sand and loamy-sand soil columns was observed to be 0.33 and 0.4 respectively based on the volume displacement method. The soil column studies were conducted for a period of 2 hours and 29.7, 3.98, 11.42 pore volumes of DI water passed through sand and loamy-sand soil columns respectively. Around 30 to $40 \mathrm{~mL}$ of leachate samples was collected from the soil columns at regular intervals (Figure 3.6) and were analyzed for LA35, Bacteroidales, E. coli, Enterococcus sp., and S. Typhirium by qPCR. The variations in the microbial concentrations in the leachate from sand, loamy-sand, and replicate loamy-sand soil column studies were compared to each other and are plotted in Figure 3.7. Note that the microbial concentrations were absolute values and not log transformed before calculating the C/Co values for the plots in Figure 3.7. 


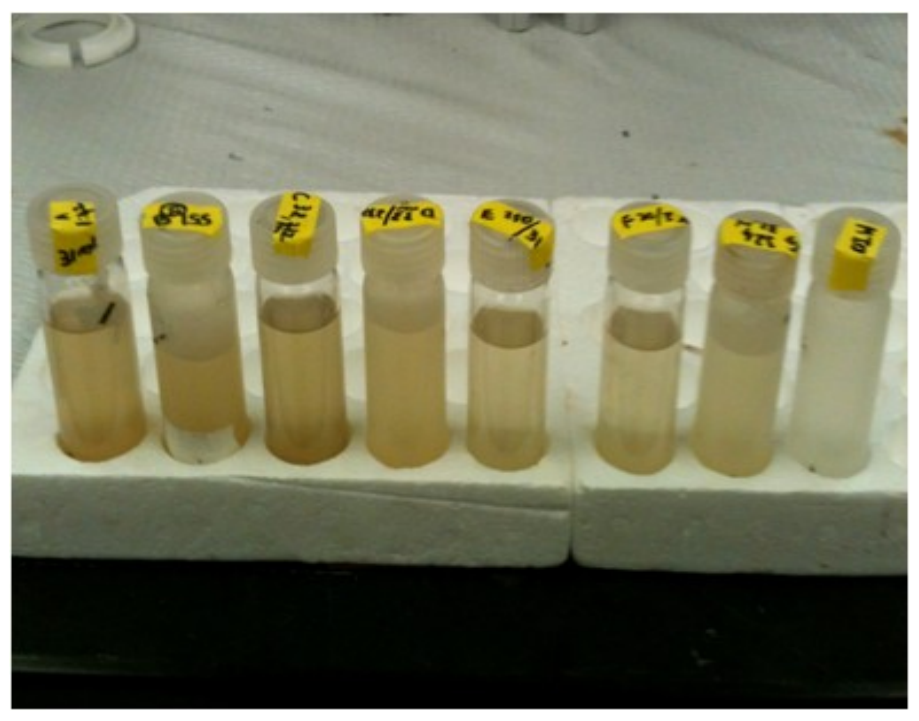

Figure 3.6 Leachate samples collected from replicate loamy-sand soil column study. The samples proceed in order from first collected on the left to last collected on the right in the figure.

The sand column study was conducted for a period of $120 \mathrm{~min}$ and the breakthrough of microorganisms were observed at 20 min i.e., at 4.88 pore volumes. The log concentrations of LA35, Bacteroidales, E. coli, Enterococcus sp., and S. Typhirium at 4.88 pore volumes in a sand column were observed to be 5.24, 9.19, 9.38, 11.51 and $10.75 \log$ gene copies $\mathrm{L}^{-1}$ respectively. A spike in the microbial concentrations occurred at 4.88 pore volumes and then decreased sharply.

The loamy-sand soil column study was conducted twice as the water stopped draining in the first loamy-sand soil column study. A total of 3.98 pore volumes i.e., $112 \mathrm{~mL}$ of DI water was passed through the first loamy-sand soil column in $42 \mathrm{~min}$. A significant breakthrough of microbial concentrations was observed for E. coli and LA35, at 1.68 to 2.0 pore volumes. The microbial concentrations of LA35, Bacteroidales, E. coli, Enterococcus sp., and S. Typhirium at 1.68 pore volumes were observed to be $6.7,8.88,6.28,6.75$ and $7.82 \log$ gene copies $\mathrm{L}^{-1}$ respectively. However the peak concentration of Bacteroidales $\left(9 \log\right.$ gene copies $\left.\mathrm{L}^{-1}\right)$ and 
Enterococcus $\left(8.29 \log\right.$ gene copies $\left.\mathrm{L}^{-1}\right)$ occurred at 1.1 pore volumes, while the peak concentration of Salmonella sp. (8.99 log gene copies L ${ }^{-1}$ ) occurred in the first sample collected at 0.57 pore volumes (Figure 3.7B). The microbial concentrations for LA35 and E. coli peak at 2.0 pore volumes and then decreased gradually in the first loamy-sand soil column. In the replicate loamy-sand soil column study a total of 11.42 pore volumes i.e., $562 \mathrm{~mL}$ of DI water was passed through the loamy-sand soil column in a period of $120 \mathrm{~min}$. A total of 14 leachate samples were collected and were analyzed by qPCR. The breakthrough of microbial concentrations was observed at 4.55 pore volumes in replicate loamy-sand soil column study (Figure 3.7C). However the peak concentration of Bacteroidales ( $7 \log$ gene copies $\mathrm{L}^{-1}$ ) and Enterococci $\left(6.68 \log\right.$ gene copies $\left.\mathrm{L}^{-1}\right)$ occurred between 4 and 6 pore volumes, while the peak concentration of Salmonella sp. (11.15 log gene copies $\left.\mathrm{L}^{-1}\right)$ occurred in the first sample collected at 0.67 pore volumes (Figure 3.7C). The early peak concentrations of LA35, Bacteroidales, E. coli, Enterococcus sp., and S. Typhirium were observed to be 5.47, 7.94, 6.75, 8.65, and 10.49 $\log$ gene copies $\mathrm{L}^{-1}$ respectively (Figure 3.7). 

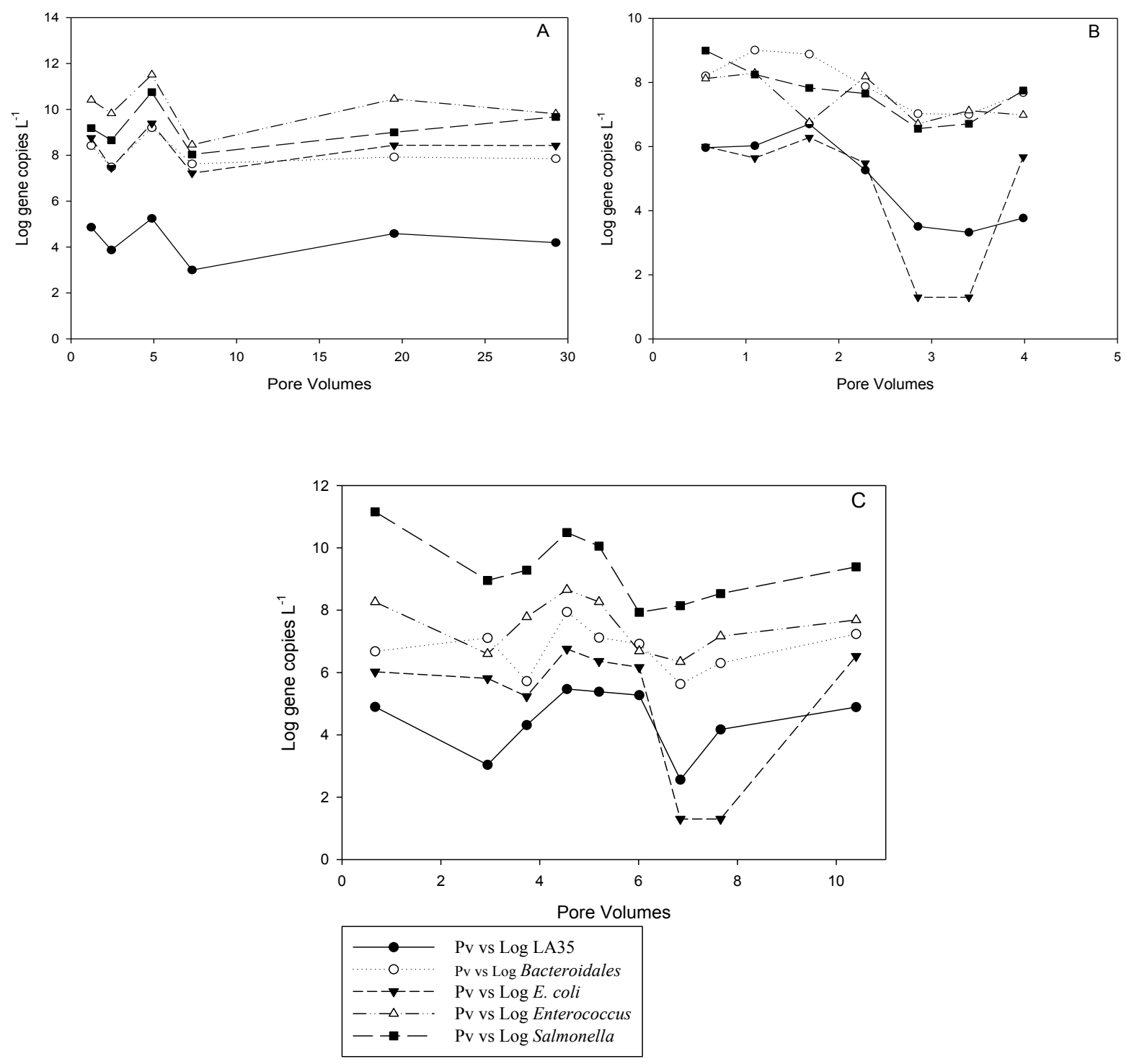

Figure 3.7 Represents relative changes in log gene copies $\mathrm{L}^{-1}$ of microbial concentrations in leachate samples from sand column (A), loamy-sand soil column (B), replicate loamy-sand soil column (C).

A gradual increase in the microbial concentrations was observed in the leachate samples collected from 3 to 5.2 pore volumes. The microbial concentrations reduced after 5.2 pore volumes until approximately 8 pore volumes when another mass of microorganisms passed through the column and graphically an increase in concentrations were observed. 
LA35 showed significant positive correlation with E. coli $(\mathrm{n}=5, \mathrm{r}=0.99, \mathrm{p}<0.001)$, Enterococcus sp. $(\mathrm{n}=5, \mathrm{r}=0.99, \mathrm{P}<0.001)$, Bacteroidales $(\mathrm{n}=5, \mathrm{r}=0.99, \mathrm{P}=0.002)$, and $S$. Typhirium $(\mathrm{n}=5, \mathrm{r}=0.98, \mathrm{P}<0.001)$ in the leachate samples collected in sand column study. In loamy-sand soil column studies concentrations of LA35 positively correlated with only E. coli (n $=19, \mathrm{r}=0.86, \mathrm{P}<0.001)$, and Bacteroidales $(\mathrm{n}=16, \mathrm{r}=0.63, \mathrm{P}=0.004)$, also in replicate loamy-sand column studies LA35 positively correlated with only E. coli $(\mathrm{n}=13, \mathrm{r}=0.9, \mathrm{P}<$ 0.001), and Bacteroidales $(\mathrm{n}=13, \mathrm{r}=0.6, \mathrm{P}=0.02)$
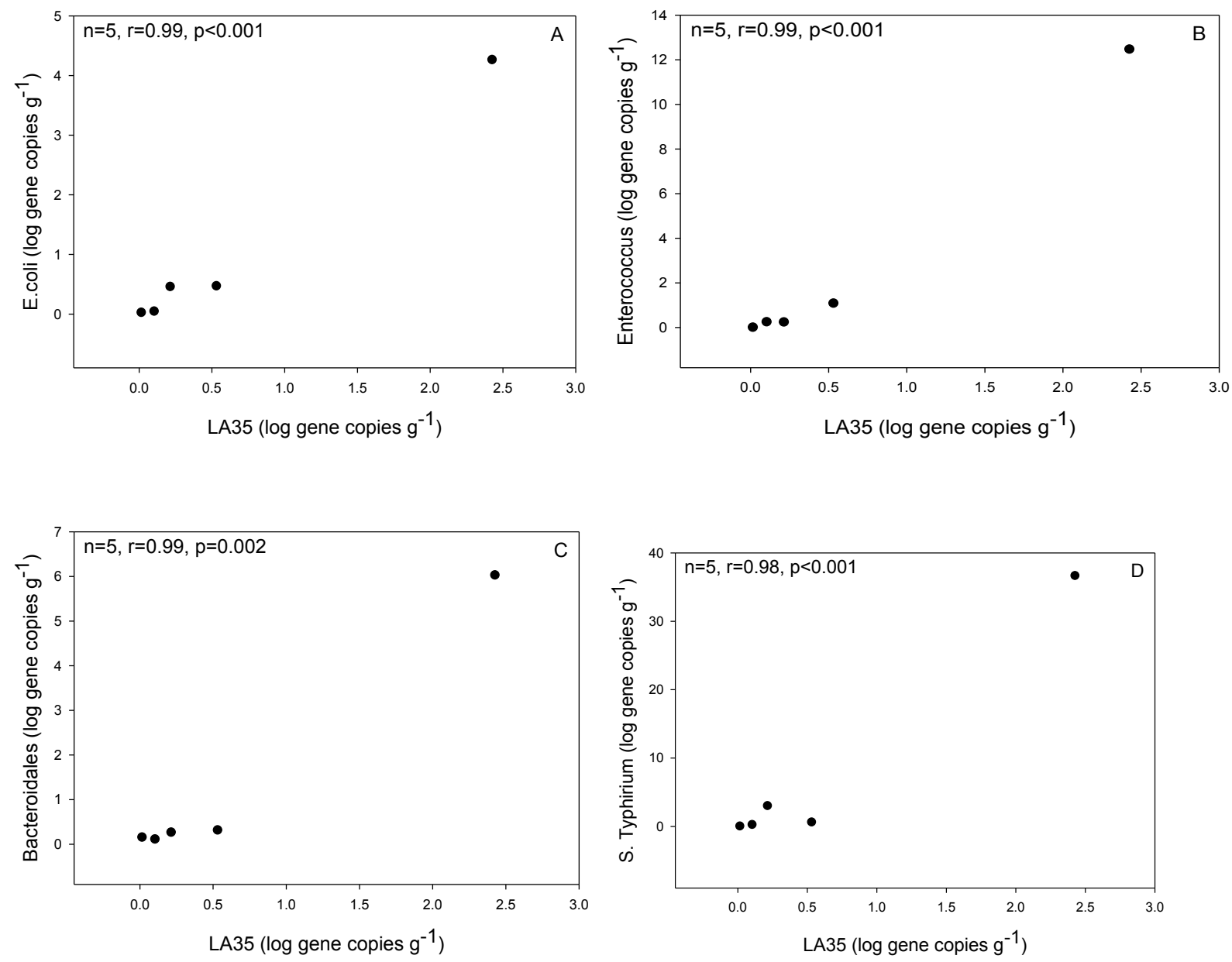

Figure 3.8 Correlation of LA35 with E. coli, Enterococcus sp., Bacteroidales and S. Typhirium in sand column leachate samples by qPCR methods. 

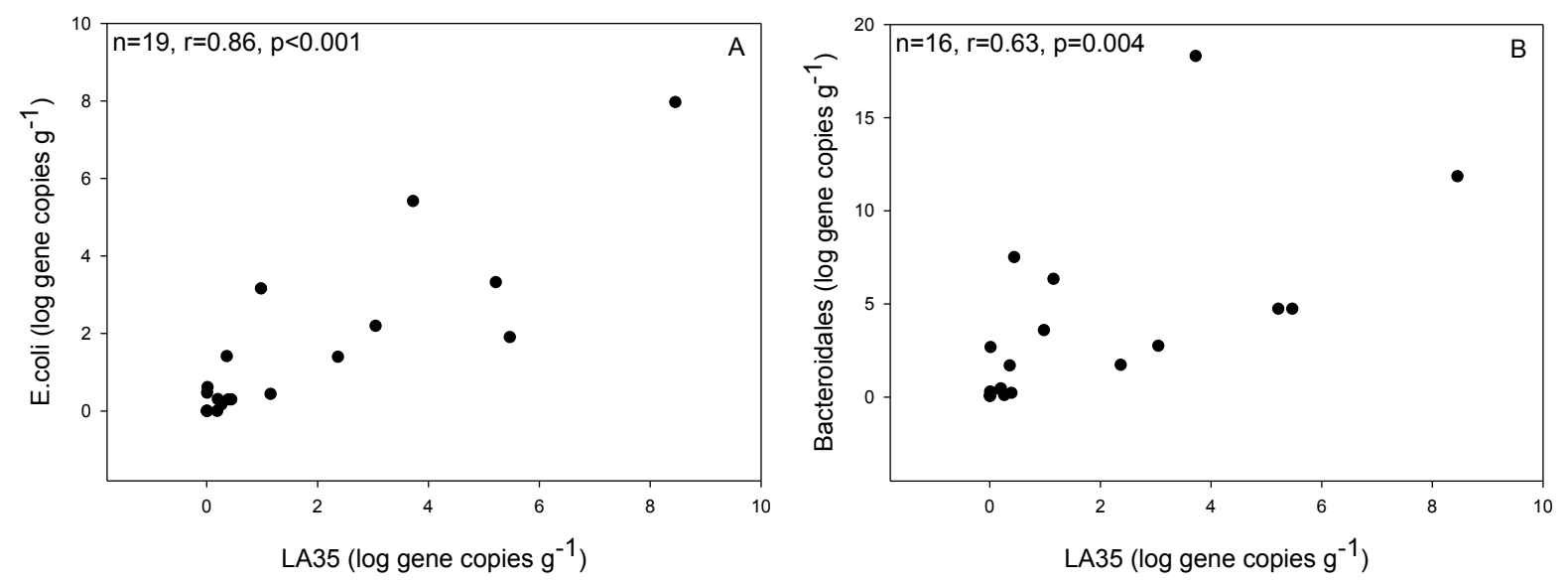

Figure 3.9 Correlation of $L A 35$ with E. coli and Bacteroidales sp. in the leachate samples collected in the loamy-sand soil column study.
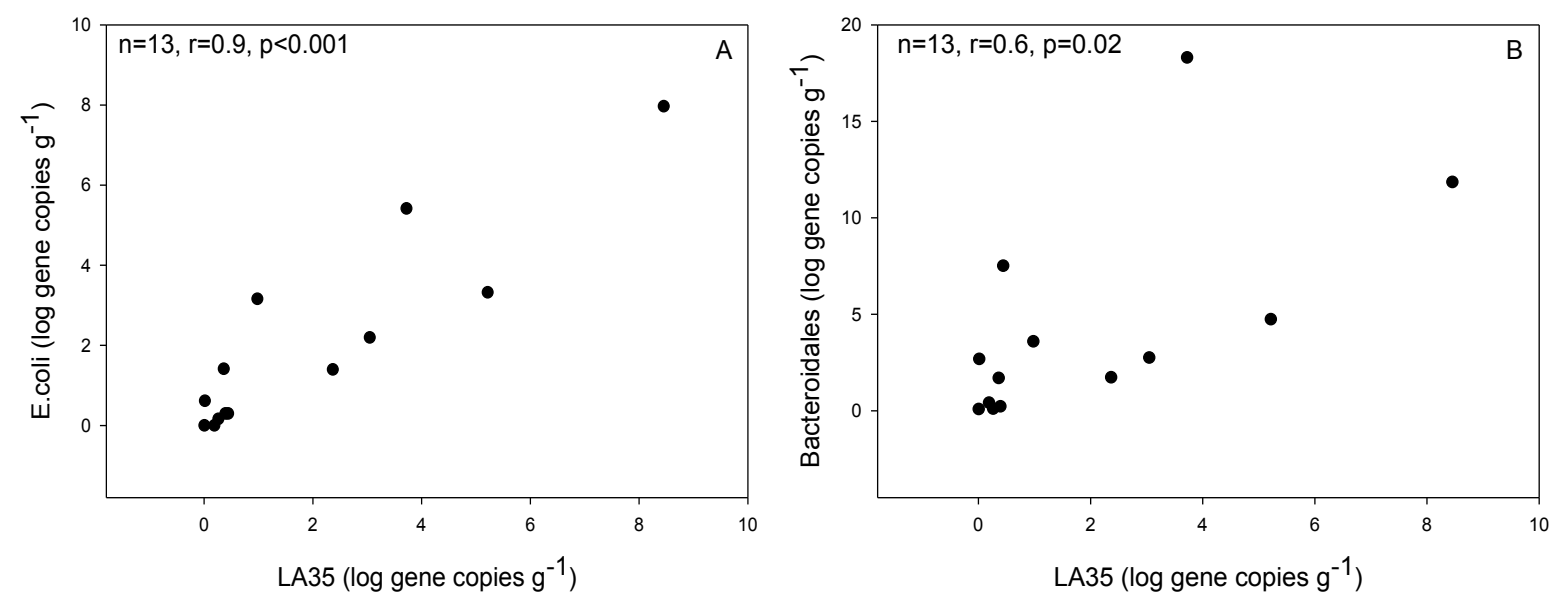

Figure 3.10 Correlation of LA35 with E. coli and Bacteroidales sp. in the leachate samples that were collected during replicate loamy-sand soil column study. 

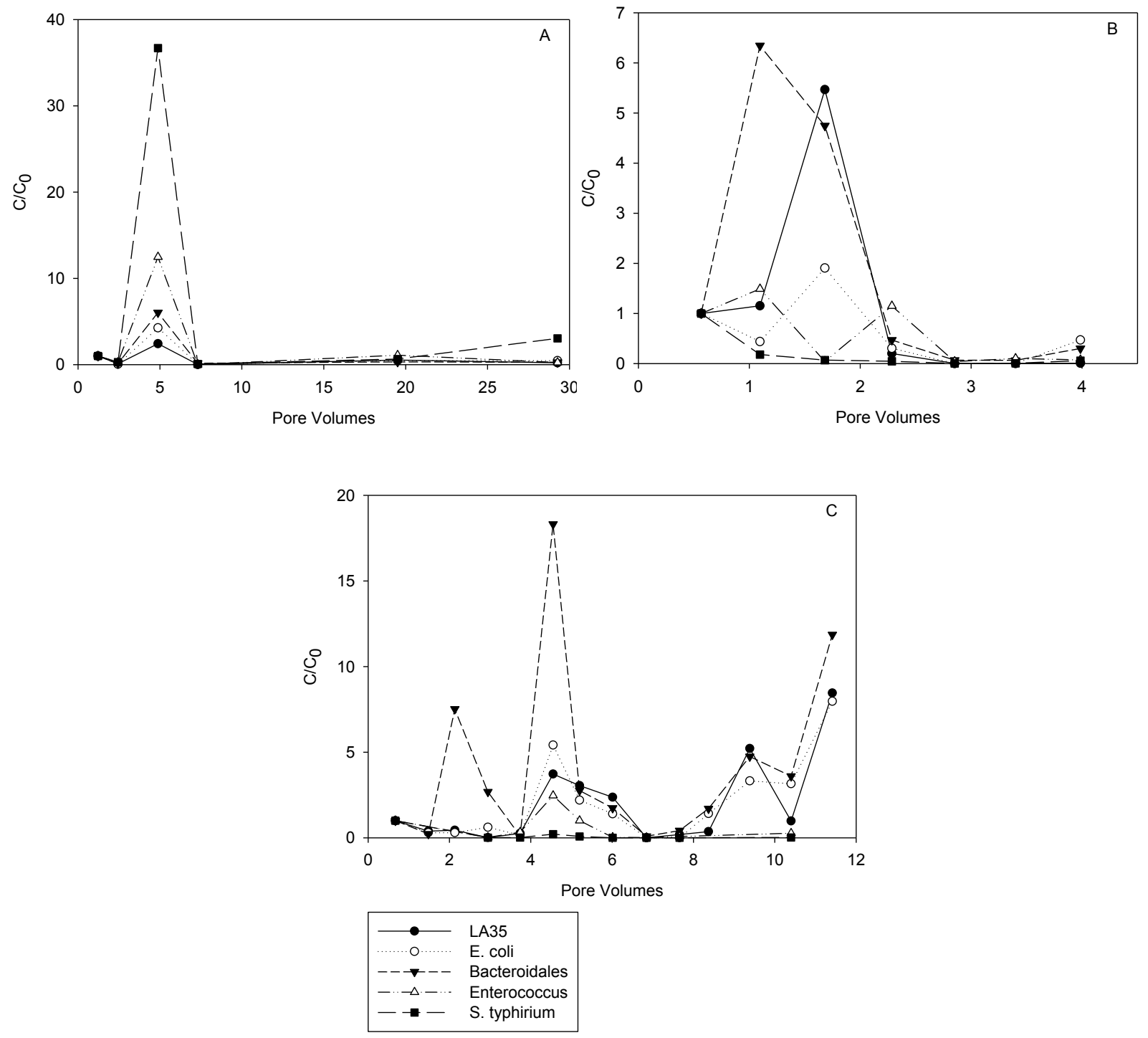

Figure 3.11 Represents relative changes in $\log$ gene copies $\mathrm{L}^{-1}$ of microbial concentrations in leachate samples from sand column (A), loamy-sand soil column (B), replicate loamy-sand soil column $(\mathrm{C}) . \mathrm{C}_{0}$ is the microbial concentrations present in the first leachate samples collected.

\subsubsection{Microbial concentrations in soil columns}

Concentrations of LA35, Bacteroidales, E. coli, Enterococcus sp. and S. Typhirium at varying depths in the soil column (i.e., $0-4,4-8.5,8.5-12 \mathrm{~cm}$ ) in the soil column studies are 
plotted in Figure 3.9. For the loamy-sand soil column studies, the average microbial concentration in both loamy-sand soil column studies was plotted and their standard deviations are shown with error bars. The $0 \mathrm{~cm}$ depth microbial concentrations are the concentrations observed in the poultry litter prior to the initiation of the studies, not after completion of the studies. In general a decrease in microbial concentrations was observed with increasing in depth in the soil columns. It was observed that the soiled poultry litter (wood shavings and poultry feces) added on the top of soil columns contained the highest microbial concentrations compared to the soil samples. The top soil layer depth $0-4 \mathrm{~cm}$ in sand column contained higher microbial concentrations compared to deeper sections in the soil column. Higher retention was observed for Salmonella sp (i.e., a greater absolute reduction in Salmonella sp. concentrations in the columns compared to the concentrations in the soiled litter). In the last column depth (i.e., 8.5 to $12 \mathrm{~cm}$ ) a total of 2 to $3 \log$ reduction decrease of all microorganisms was observed in the sand columns compared to approximately 2 to 4 log reductions in loamy-sand columns. Trend lines were drawn to compare the slope of reduction in microbial concentrations with depth. It was observed that the FIB (E. coli and Enterococcus sp.) follow similar reductions in concentrations in both sand and loamy-sand soil columns. No significant correlation was observed in the concentration of LA35 with depth compared to the concentration of other microorganisms observed in the soil column studies. 

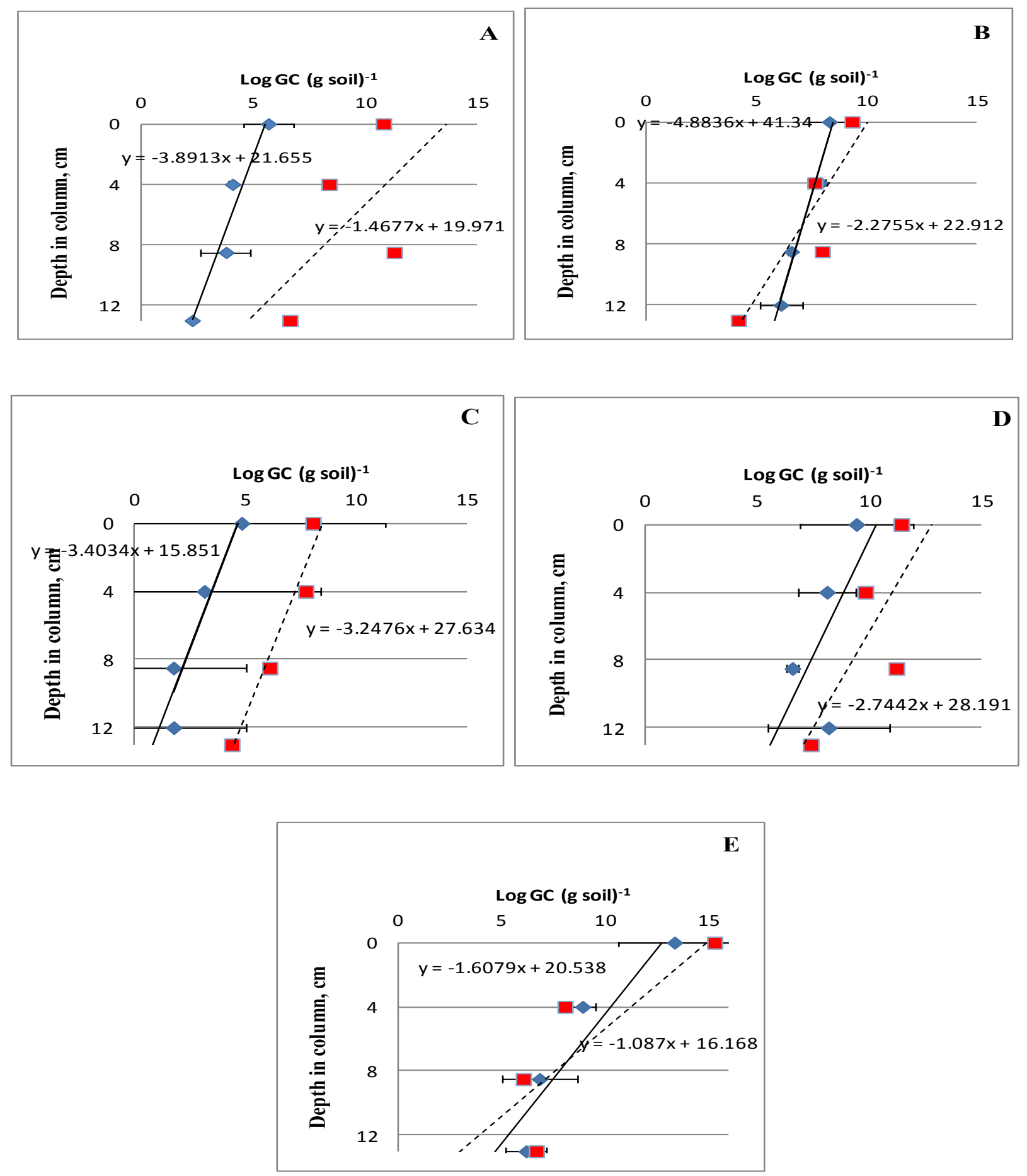

Figure 3.12 Concentrations of LA35 (A), Bacteroidales (B), E. coli (C), Enterococcus sp. (D), and Salmonella sp. (E) in sand column (squares) and loamy-sand soil column (diamonds) with depth. The dashed trendline is added for sand column and solid trendline is added for loamy-sand column. 


\section{DISCUSSION}

Growth Vs Deposition. In the deposition study we observed an increase in microbial concentrations in poultry litter with the increase in age of birds. Two possible mechanisms could have resulted in increasing concentrations of microorganisms on the litter 1) microorganism deposition or 2) growth of microbes in the litter after deposition. Our results suggest this increase in microbial concentrations was due solely to deposition of microorganisms in poultry feces onto the poultry litter for LA35 and E. coli. This result is supported by our observation by culture based methods of declining $E$. coli concentrations in the tubes incubated in the pens separate from additional poultry feces inputs (Figure 2.4). In contrast both deposition and growth likely occurred for Staphylococcus sp. and Enterococcus sp. during our study (Figure 2.5B and 2.6B). It was observed clearly that concentrations of all microorganisms (E. coli, Enterococcus sp., LA35 and Staphylococcus sp.) tend to increase after 4 to 5 weeks by culturebased methods. A minimum of $2 \pm 0.5 \log$ gene copies $\mathrm{g}^{-1}$ increase was observed in E. coli and Staphylococcus sp.

Both E. coli and Enterococcus sp. are FIB and are present in the feces of poultry birds (Kelley et al., 1995). It was observed that the initial concentrations of FIB in fresh litter during first week of placement of birds are very high. These microbial concentrations tend to decrease when the poultry litter was kept away from contact with poultry litter in pens likely due to decay of the microbes. It was also observed that when they re-utilized this aged poultry litter as bedding for more birds, the microbial concentrations gradually increased again.

The microbial community in poultry litter is mainly due to deposition of microbes from the chicken gut to the litter (Lu et al., 2003). As poultry birds mature the microbial population 
changes in the gastrointestinal tracts of birds from simple and transient communities to one of increasing complexity (Lu, et al., 2003). The Lu et al., study also included a description of the relative proportions of different bacterial lineages in the chicken gut as the birds mature. Beyond inoculation of litter, from chicken feces the poultry litter microbial community is also influenced by number of birds in the pen, age of birds, and bird's diet. The microbial diversity in poultry litter was influenced by $\mathrm{pH}$, temperature and moisture content (Liu et al., 2007; Lovanh et al., 2007; S. Wadud et al., 2012). In a study conducted by Northcutt et al., 2002 cotton plugs were placed in cloaca of birds and were analyzed at the time of slaughtering of birds. E. coli, total coliforms, Campylobacter and Salmonella were recovered from carcasses of birds and it was reported that their concentrations increase with the bird's age. In contrast the concentrations of Campylobacter were higher in 42 day old age broilers compared to 49 and 52 day old broiler chickens. More manure is produced by adult birds $(>4 \mathrm{lb})$ compared to chicks. It was observed that a $4 \mathrm{lb}$ broiler chicken produces 28-40 lb manure per year (Labaden et al., 2000). Hence it was observed that as the birds grow older they produce more manure which in turn deposits more microorganisms on bedding. However other factors that affect the concentrations of microorganisms in a pen depends on the number of birds in each pen, bird's diet, bedding moisture content and temperature at the farm.

Correlation between culture and qPCR methods. In the deposition study we analyzed the microbial concentrations in poultry litter by both culture-based and qPCR methods. We also tested if there was a correlation between these results. In these studies there was not a correlation between the culture-based and qPCR methods used for the analysis of FIB (E. coli and Enterococcus sp.) in poultry litter samples analyzed in the deposition study. In contrast a study conducted by R. A. Haugland et al., 2004 revealed that there exist a significant positive 
correlation coefficient $(\mathrm{r}=0.68)$ between culture and $\mathrm{qPCR}$ based methods used to test for Enterococcus sp. The authors used the same culture and qPCR based assays we used in this study to test for Enterococcus sp. in water samples collected from Lake Erie $(\mathrm{n}=47)$ and Lake Michigan $(n=56)$. In a study conducted by Noble et al., 2010 they compared culture-based and qPCR methods for E. coli and Enterococcus sp. in water samples collected from recreational beaches in California. Overall it was observed that both showed a significant positive correlation $(\mathrm{r}>0.69)$. The agreement of results between results of Enterococcus sp. qPCR and EPA method 1600 was $88 \%$.

In contrast to the results presented by others above, the results obtained in our deposition study did not show a correlation between culture and qPCR based results. Possible reasons for this difference include first the frequent sampling of poultry litter weekly, soon after the deposition of feces allowing little time for the reassimilation of dead cell debris including nucleic acids. Whereas the water samples may have been exposed to Enterococcus sp. for a long time allowing for greater equilibrium between live and dead cells. Second, poultry litter is relatively rich in nutrients compared to water samples that are likely low in carbon content and hence there would be more rapid utilization of dead cells as a food source in water samples compared to poultry litter samples.

In another study conducted by Converse et al., 2012 the correlations between qPCR and culture-based methods varied with the time of sampling. It was observed that correlations were higher in the morning $(0.45<\mathrm{r}<0.74[p<0.002])$ than in the afternoon $(0.18<\mathrm{r}<0.45[p<0.021]$ in the beach water samples. The tubes that were hung in the deposition study herein were observed for growth or decay in samples kept away from poultry inputs. E. coli concentrations 
decreased over a period of time by culture-based methods. However they did not show any significant decrease in concentrations by qPCR methods. Based on these culture-based results one cannot conclude that $E$. coli cells are dying in poultry samples hung away from poultry inputs. Researches by different microbiologists confirm that bacteria enter a state called viable but not cultivable state (VBNC).

The bacteria in a VBNC state failed to grow on regular bacteriological media but are alive and capable of metabolic activity (Oliver 2005, Oliver 2000b). It was observed that the $E$. coli 0157:H7 (EHEC) strain produce toxins in a VBNC state (W. Rigsbee et al., 1996). Hence it is necessary to know that live and viable but not cultivable cells may be present in the samples. However, other researchers think that qPCR overestimates the count of cells by including measurement of dead cells present as DNA. For example, when some microorganisms were exposed to UV light and are quantified by culture and qPCR methods, the concentrations by culture-based methods showed reduction in values whereas qPCR did not (Whiteman et al., 2004).

Release and transport of land applied poultry litter. An understanding of bacterial migration and transport with water over and into agricultural soils where manure has been applied as fertilizer is necessary to assess the risk that pathogenic microorganisms pose to water resources (Ginn et al., 2002). We conducted a soil column study to evaluate correlations between the release and transport mechanisms of LA35 with other microorganisms present in poultry litter through soil columns. It was observed that the breakthrough of LA35 in leachate samples collected from a sand column showed significant positive correlation with E. coli, Enterococcus sp., Bacteroidales and S. Typhirium. The breakthrough of LA35 in the effluent from an loamysand column showed significant positive correlations with E. coli and Bacteroidales sp. and 
Enterococcus $\mathrm{sp}$. (Pearson's correlation, $\mathrm{n}=21, \mathrm{r}=0.54 ; \mathrm{p}=0.029$ ). It was also observed that the bacterial concentrations tend to decrease with depth in sand and loamy-sand soil columns, suggesting attenuation of microorganisms. However, we observed no correlation between the transport mechanisms of various microorganisms with respect to LA35 in both sand and soil columns with depth in soil columns. Both physical factors (colloid size and grain size distribution) and chemical factors (surface charge of colloid and porous media) affect the transport of microorganisms in soil column (Scott et al., 2002).

The decrease in microbial concentrations in the soil column may be due to 1) bacterial sorption to soil particles, 2) slow detachment of bacteria over time, 3) filtering mechanisms 4) number of sorbing sites. In a sand column study conducted by G.Gargiulo et al., 2008 two bacterial strains Deinococcus radiodurans and Rhodococcus rhodochrous exhibited differential transport mechanisms likely due to hydrophobicity of the microbes. Both microorganisms have the same physical properties such as cell structure, gram stain, size, and hydrophobicity characteristics. They were observed to form aggregates in solution. However, the hydrophobic $R$. rhodochrous tended to form larger aggregates. It was also observed that the decrease in water content led to decreases in effluent concentrations and increase in retention of bacteria in the sand column. It was observed that the bacterial concentrations in sand column were deposited in the first few cm in column depth and gradually decreased with increased depth. In Johnson et al., 1995 it was reported that the bacterial breakthrough in a field site is a result of pulse injection of bacteria, which is a function of influent concentration and number of irreversibly sorbing sites in the porous media. Todd et al., 2012 reported on the detachment mechanisms of Enterococcus in naturally contaminated beach sands and their transport to groundwater table via infiltrating sea water during field and modeling experiments. The detachment mechanisms are associated with 
rapid increase in pore water content. Likely reasons for the mobility of Enterococcus in the investigated system include air- water interface scouring and thin film expansion.

Hence we observed that the bacterial concentrations in soil columns decreased with depths may be due to the bacterial sorption of particles in the soil columns, also their tendency to form colloidal particles with air- water interface, these larger particles are difficult to pass through the pores in the soil columns. Soil column acts as a filtering membrane and hence flows of microorganisms along its depth vary depending on the types of soil present in the column.

Suitability of LA35 as poultry marker. In this study we reported on the persistence and growth dynamics of the poultry marker gene Brevibacterium sp. LA35 with respect to E. coli, Enterococcus sp., Bacteroidales, and Staphylococcus sp. in a deposition study. First, LA35 concentrations were not present in bedding not exposed to poultry and increased over time in the litter due to deposition of poultry feces. Second, the concentrations of LA35 due to deposition in poultry litter correlated with the FIB present in poultry litter. Specifically, it was observed that the concentrations of LA35 showed significant positive correlation with Enterococcus and Staphylococcus sp. present in the poultry litter samples in the deposition study, also transportation of LA35 showed positive correlation with E. coli, Enterococcus sp., Bacteroidales sp., and Salmonella sp. in the sand column.

LA35 was not detected in poultry litter until 4 weeks of age. In contrast to these results it was previously reported that LA35 was found in lower concentrations in 1-week old baby chicks placed on litter (Weidhaas and Lipscomb 2013), however the pens had not been cleaned prior to placement of the chicks on the litter reported in that study (data not presented). Variations in LA35 in poultry feces may be due to differing physical conditions of the birds, the poultry bedding used, feed characteristics, physical sampling error, and litter moisture and $\mathrm{pH}$. 
The increase in LA35 observed in the FW samples was likely due to deposition of poultry feces. LA35 was not detected in any of the non-target fecal samples (Weidhaas and Lipscomb 2013) and chicken feed (this study), hence the TaqMan qPCR was found to be $100 \%$ specific. LA35 was identified in the all the samples that were tested in soil column studies. The breakthrough of microbial concentrations in sand and loamy-sand columns were observed at 5 pore volumes and more time lag was observed in the loamy-sand column compared to the sand column. It was observed that the concentrations of LA35 positively correlated with E. coli, Bacteroidales, and $S$. Typhirium in sand column leachate samples whereas LA35 positively correlated with E. coli, Enterococcus, and Bacteroidales in the leachate samples collected from loamy-sand soil samples.

\section{CONCLUSIONS AND FUTURE RESEARCH}

The overall conclusions from the two studies that were conducted to determine the suitability of LA35 as a MST marker and the correlations of microorganisms evaluated in these studies with respect to LA35 are as follows:

- The increase in microbial concentrations in FW samples was due to increase in deposition of feces in poultry litter with the increase in bird's age.

- The marker is correlated to FIB and pathogens in both the studies and therefore is a likely candidate for further consideration for regulating water quality in poultry impacted areas.

- The LA35 abundance in primary and secondary habitat is related. High concentrations of LA35 in poultry litter resulted in high concentrations in leachate samples. 
- The Brevibacterium sp. LA35 correlated with the Enterococcus and Staphylococcus concentrations obtained by culture-based methods in the deposition study samples.

- In soil column studies transport behavior of Brevibacterium sp. LA35 correlated with (E. coli, Enterococcus sp., Bacteroidales, and S. Typhirium) in sand columns and (E. coli, and Bacteroidales) in loamy-sand soil columns.

- LA35 did not correlate with the microorganisms present along the depth of the soil columns.

The recommendations for future research based on the results of this study and the review of the literature are as follows:

- There was no correlation between the results obtained by culture-based and qPCR methods in the deposition study. However to address if there is a significant decay or growth in the samples not further exposed to poultry feces further research is necessary to differentiate dead cells from live and VBNC cells.

- Future studies must validate the soil column study with aged litter, stacked litter and in different soil types and land application strategies (i.e., slurry injections).

\section{REFERENCES}

1. Aislabie J., Smith J. J., Fraser R., McLeod M. "Leaching of bacterial indicators of faecal contamination through four New Zealand soils." Australian Journal of Soil Research, 2001: 39,1397-1406.

2. APHA. "Standard methods for the examination of water and wastewater, 21st ed." American Public Health Association, Inc., Washington,D.C., 2005. 
3. Bolster, C. H., B. Z. Haznedaroglu, and S. L. Walker.Bolster, C. H., B. Z. Haznedaroglu, and S. L. Walker. "Diversity in cell properties and transport behavior among 12 different environmental isolates." Journal of Environmental Quality, 2009: 465-472.

4. Brown, P., O. Christensen, H. Clough, P. Diggle, C. Hart, S. Hazel, R. Kemp, A. Leatherbarrow, A. Moore, J. Sutherst, J. Turner, N. Williams, E. Wright, and N. French. "Frequency and special distribution of environmental Campylobacter spp." Appl. EnviMicrobiol, 2004: 70:6501-6511.

5. Catherine A. Kelty, Manju Varma, Mano Sivaganesan,Richard A. Haugland and Orin C. Shanks. "Distribution of genetic marker concentrations for fecal indicator bacteria in sewage and animal feces." Applied and Environmental Microbiology, 2012: 78(12):4225.

6. Converse, Reagan R., John F. Griffith, Rachel T. Noble, Richard A. Haugland, Kenneth C. Schiff, and Stephen B. Weisberg. "Correlation between quantitative PCR and culture-based methods for measuring Enterococcus spp. over various temporal scales at three California marine beaches." Applied and Environmental Microbiology , 2012: 1237-1242.

7. Dae-Young Lee, Heather Lauder,Heather Cruwys,Patricia Falletta,Lee A. Beaudette. "Development and application of an oligonucleotide microarray and real-time quantitative PCR for detection of wastewater bacterial pathogens." Science of the total environment, 2008: 398: 203-211.

8. In Principles of geotechnical engineering, by Braja M. Das, Chapter 2. Brooks/Cole Publishing Co, 5th ed.

9. G. Gargiulo, S. A. Bradford, J. Simunek, P. Ustohal, H. Vereecken, and E. Klumpp. "Bacteria transport and deposition under unsaturated flow conditions: The Role of Water Content and Bacteria Surface Hydrophobicity." Vadose Zone Journal, 2008: 7:406-419.

10. Gautam, Pujya Wagle. " Spatial relationship between the trichloroethylene degrading bacteria Dehalococcoides sp., and sulfate reducers and Archaea during reductive dechlorination." PhD diss., West Virginia University Libraries, 2013.

11. Ginn, T.R., B.D. Wood, K.E. Nelson, T.D. Scheibe, E.M. Murphy, and T.P.Clement. "Processes in microbial transport in the natural subsurface." Adv. Water Resour., 2002: 25:1017-1042.

12. Griffiths, R., A. Whiteley, A. O'Donnell, and M. Bailey. "Rapid method for coextraction of DNA and RNA from natural environments for analysis of ribosomal DNA-and rRNA- based microbial community composition." Appl. Envion. Microbiol, 2000: 66: 5488-5491.

13. Hodon Ryu, Michael Elk, Izhar U.H. Khan, Valerie J. Harwood, Marirosa Molina, Thomas A. Edge, Jorge Santo Domingo. "Comparison of two poultry litter qPCR assays targeting the 16S rRNA gene of Brevibacterium sp." Water Research, 2014: 613-621. 
14. J. K. Northcutt, M. E. Berrang, J. A. Dickens, D. L. Fletcher, and N. A. Cox. "Effect of broiler age, feed withdrawal, and transportation on levels of Coliforms, Campylobacter, Escherichia coli and Salmonella on carcasses before and after immersion chilling." Poultry Science, 2003: 82:169173.

15. J.L. Weidhaas, T.W. Macbeth, R.L. Olsen, M.J. Sadowsky, D. Norat and V.J. Harwood. "Identification of a Brevibacterium marker gene specific to poultry litter and development of a quantitative PCR assay." Journal of Applied Microbiology, 2009: 109(1):334-47.

16. Jennifer L. Weidhaas, Tamzen W. Macbeth, Roger L. Olsenand Valerie J. Harwood. "Correlation of quantitative PCR for a poultry-specific Brevibacterium marker gene with bacterial and chemical Indicators of water pollution in a watershed impacted by land application of poultry litter." Appl. Environ. Microbiol, 2011: 77.6: 2094-2102.

17. Johnson, William P., and Gary L. Amy. "Facilitated transport and enhanced desorption of polycyclic aromatic hydrocarbons by natural organic matter in aquifer sediments."

Environmental Science \& Technology, 1995: 807-817.

18. Kelley, Timothy R., Oscar C. Pancorbo, William C. Merka, Sidney A. Thompson, Miguel L. Cabrera, and Harold M. Barnhart. "Bacterial pathogens and indicators in poultry litter during reutilization." The Journal of Applied Poultry Research, 1995: 366-373.

19. Liu, Wen-Tso, Terence L. Marsh, Hans Cheng, and Larry J. Forney. "Characterization of microbial diversity by determining terminal restriction fragment length polymorphisms of genes encoding 16S rRNA." Applied and Environmental Microbiology, 1997: 4516-4522.

20. Liu, Z., Wang, L., Beasly, D. \& Oviedo. "Effect of moisture content on ammonia emissions from broilerlitter: a laboratory study." Journal of Atmospheric Chemistry, 2007: 58:41-53.

21. Lovanh, N., Cook, K.L., Rothrock, M.J., Miles, D.M. \& Sistani, K. "Spatial shifts in microbial population structure within poultry litter associated with physicochemical properties." Poultry Science, 2007: 86:1840-1849.

22. Lu, J., Idris, U., Harmon, B., Hofacre, C., Maurer, J. and Lee, M.D. "Diversity and succession of the intestinal bacterial community of the maturing broiler chicken." Applied and Environmental Microbiology, 2003: 69: 6816-6824.

23. M. C. Labadan, Jr.,1 K.-N. Hsu, and R. E. Austic. "Lysine and Arginine requirements of broiler chickens at two- to three-week intervals to eight weeks of age." Poultry Science 80:599-606, 2001.

24. Noble, Rachel T., A. Denene Blackwood, John F. Griffith, Charles D. McGee, and Stephen B. Weisberg. "Comparison of rapid quantitative PCR-based and conventional culture-based methods for enumeration of Enterococcus spp. and Escherichia coli in recreational waters." Applied and Environmental Microbiology, 2010: 7437-7443. 
25. Oliver, James D. "The public health significance of viable but nonculturable." Springer US, 2000: 277-299.

26. Oliver, James D. "The viable but nonculturable State in Bacteria." The Journal of Microbiology, 2005: 93-100.

27. Pearson, Karl. "Notes on regression and inheritance in the case of two parents." Proceedings of the Royal Society of London, 1895: 58:240-242.

28. Poljak M, Barlic J, Seme K, Avsic-Zupanc T \& Zore A. "Isolation of DNA from archival papanicolaou stained cytological smears using a simple salting-out procedure." Clinical Molecular Pathology , 1995: 48: M55-M5.

29. R.Jamieson1, R.J. Gordon2, K.E. Sharples3, G.W. Stratton3 and A. Madani2. "Movement and persistence of fecal bacteria in agricultural soils and subsurface drainage water: A review." 2002, 44:1.1-1.9.

30. Rachel T. Noble, A. Denene Blackwood, John F. Griffith, Charles D. McGee, and Stephen B. Weisberg. "Comparison of rapid quantitative PCR-based and conventional culture-based methods for enumeration of Enterococcus spp. and Escherichia coli in recreational waters." Applied and Environmental Microbiology, 2010: 7437-7443.

31. Richard A. Haugland, Shawn C. Siefring, Larry J. Wymer, Kristen P. Brenner, Alfred P. Dufour. "Comparison of Enterococcus measurements in freshwater at two recreational beaches by quantitative polymerase chain reaction and membrane filter culture analysis." Water Research Journal 39 (2005) 559-568.

32. Rodgers, P., C. Soulsby, C. Hunter, and J. Petry. "Spatial and temporal bacterial quality of a lowland agricultural stream in northeast Scotland." Science of the total environment, 2003: 289302.

33. Rogers, Shane, and John Haines. "Detecting and mitigating the environmental impact of fecal pathogens originating from confined animal feeding operations." Review, 2005.

34. Russell, Todd L., Kevan M. Yamahara, and Alexandria B. Boehm. "Mobilization and transport of naturally occurring enterococci in beach sands subject to transient infiltration of seawater." Environmental Science \& Technology, 2012: 5988-5996.

35. S. Siefring, M. Varma, E. Atikovic, L. Wymer and R. A. Haugland. "Improved real-time PCR assays for the detection of fecal indicator bacteria in surface waters with different instrument and reagent systems." Journal of Water and Health , 2008: 225-237.

36. S. Wadud, A. Michaelsen, E. Gallagher, G. Parcsic, O. Zemb, R. Stuetz c \& M.Manefield. "Bacterial and fungal community composition overtime in chicken litter with high or low moisture content." British Poultry Science, 2013: 561-569. 
37. Scott A. Bradford, Scott R. Yates, Mehdi Bettahar, and Jirka Simunek. "Physical factors affecting the transport and fate of colloids in saturated porous media." Water Resources Research, 2002: 63-1.

38. Scott, Troy M., Joan B. Rose, Tracie M Jenkins, Samuel R. Farrah, and Jerzy Lukasik. "Microbial source tracking: current methodology and future applications." Appl. Environ. Microbiol, 2002: 68:5796-5803.

39. Simpson, J., J. Santo Domingo, and D. Reasoner. "Microbial source tracking: state of science critical review." Environ. Sci. Technol, 2002: 24:5279-5288.

40. Stoeckel, D. and V. Harwood. "Performance, design and analysis in microbial source tracking studies." Applied and Environmental Microbiology (Appl. Environ. Microbiol. 73:2405-2415.), 2007: 2405-2515.

41. Storer, D. A. "A simple high sample volume ashing procedure for determining soil organic matter." Commun. Soil Sci. Plant Anal, 1984: 15:759-772.

42. "The quality of our nation's waters." U.S. Environmental Protection Agency, 2000: EPA-841-S-00001.

43. Thomas, Harold A. "Bacterial densities from fermentation tube tests." American Water Works Association, 1942: 34:572-576.

44. USEPA. "Method 110 E.coli in water by membrane filtration using membrane-thermotolerant E.coli Agar (mTEC)." US Environmental Protection Agency, 2002: EPA 821-R-02-020.

45. USEPA. "Method 1600: Enterococci in water by membrane filtration using membraneEnterococcus Indoxyl-ß-D-Glucoside Agar (mEI)." US Environmental Protection Agency, Office of water., 2006: EPA 821-R-06-009.

46. Wadud, S., A. Michaelsen, E. Gallagher, G. Parcsi, O. Zemb, R. Stuetz, and M. Manefield. "Bacterial and fungal community composition over time in chicken litter with high or low moisture content." British poultry science, 2012: 561-569.

47. Walker, C. H. Bolster B. Z. Haznedaroglu and S. L. "Diversity in cell properties and transport behavior among 12 different environmental Escherichia coli isolates." Journal Environmental Quality, 2009: 38:465-472.

48. Weidhaas, J., and E. Lipscomb. "A new method for tracking poultry litter in the Potomac Basin headwaters of West Virginia." Journal of Applied Microbiology, 2013: 115.2: 445-454.

49. Whitman RL, Nevers MB, Ginger C, Korinek, Byappanahalli MN. "Solar and temporal effects on Escherichia coli concentration at a Lake Michigan swimming beach." EnvironSci Technol , 2004: 70(7):4276-4285. 
50. William P. Johnson, Karen A. Blue, Bruce E. Logan, and Robert G. Arnold. "Modeling bacterial detachment during transport through porous media as a residence-time-dependent process." Water Resorces Research, 1995: 2649-2658.

51. William Rigsbee, Linda M. Simpson and James D. Oliver. "Detection of the viable but nonculturable state in Escheriza colz 0157:H7." Journal of Food Safety, 1996: 1745-4565.

52. Wolfgang Ludwig, and Karl-Heinz Schleifer. "How quantitative is quantitative PCR with respect to cell counts." System. Appl. Microbio, 2000: 556-562. 